\title{
Learning, Forecasting and Optimizing: an Experimental Study*
}

\author{
Te Bao ${ }^{\mathrm{a}}$, John Duffy ${ }^{\mathrm{b}}$, and Cars Hommes ${ }^{\mathrm{a}}$ \\ aDepartment of Quantitative Economics, University of Amsterdam \\ Roetersstraat 11, 1018WB Amsterdam, NL \\ ${ }^{\mathrm{b}}$ Department of Economics, University of Pittsburgh \\ 4901 Wesley W. Posvar Hall, PA 15260, Pittsburgh, USA
}

October 14, 2011

\footnotetext{
*The authors are grateful to Jasmina Arifovic, George Evans, Ernst Fehr, Andrew Schotter, Theo Offerman, Lise Vesterlund, Stephanie Wang and participants of the seminar at the University of Pittsburgh, CESS-CREED Workshop and Amsterdam Symposium on Behavioral and Experimental Economics for helpful comments and stimulating discussions. We acknowledge the financial support from the EU 7th framework collaborative project "Monetary, Fiscal and Structural Policies with Heterogeneous Agents (POLHIA)" Grant No. 225048 and the Research Priority Area Behavioral Economics of the University of Amsterdam. Te Bao thanks the hospitality by the department of economics, the University of Pittsburgh and financial support by the Willems foundation during his visit to the University of Pittsburgh to work on this paper.
} 


\begin{abstract}
Rational Expectations (RE) models have two crucial dimensions: 1) agents correctly forecast future prices given all available information, and 2) given expectations, agents solve optimization problems and these solutions in turn determine actual price realizations. Experimental testing of such models typically focuses on only one of these two dimensions. In this paper we consider both forecasting and optimization decisions in an experimental cobweb economy. We report results from four experimental treatments: 1) subjects form forecasts only, 2) subjects determine quantity only (solve an optimization problem), 3) they do both and 4) they are paired in teams and one member is assigned the forecasting role while the other is assigned the optimization task. All treatments converges to Rational Expectation Equilibrium (REE), but the at very different speed. We observe that performance is the best in treatment 1) and worst in the treatment 3). Most forecasters use an adaptive expectations rule. Subjects are less likely to make conditionally optimal production decision for given forecasts in treatment 3) where the forecast is made by themselves, than treatment 4) where the forecast is made by the other member of the team, which confirms "two heads are better than one" in finding REE.

JEL Classification: C91, C92, D83, D84
\end{abstract}

Keywords: Learning, Rational Expectations, Optimization, Experimental Economics, Bounded Rationality. 


\section{Introduction}

Rational Expectations (RE) macroeconomic models have two crucial dimensions: 1) Agents use the model to correctly forecast future prices given all available information, that is, they do not make systematic mistakes. 2) Given expectations, agents solve an optimization problem to determine their consumption or production decisions, which then, via market clearing, determines the realization of the price level they were seeking to forecast. Thus, RE systems are self-referential and assume rational, optimizing behavior on the part of agents. Testing such models in controlled laboratory experiments has proved difficult owing to the complicated nature of $\mathrm{RE}$ models. As Nobel Prize laureate Sargent (2008) observes:

"Laboratory experiments using macroeconomics are rarer than those using microeconomics...I suspect that the main reason for fewer experiments in macro than in micro is that the choices confronting artificial agents within even one of the simpler recursive competitive equilibria used in macroeconomics are very complicated relative to the settings with which experimentalists usually confront subjects."

Experimentalists seeking to test RE macro models have dealt with the complicated nature of these models by reducing the dimensionality of the problem that subjects face. Two approaches have been taken.

In a "learning to forecast experiment, " - a design first proposed by Marimon and Sunder (1993) - subjects are asked to submit a forecast for a future economic variable (e.g., a price, inflation rate, foreign exchange rate, etc.), and they are rewarded solely on the basis of the accuracy of their forecast. Their forecast is then used as an input by a computer program to determine each individual's optimal quantities, as if the subjects themselves were capable of solving the optimization problem conditional on their forecast. The computer-determined quantities together with market clearing conditions determine actual price realizations (or the forecast variable of interest), and these realizations are then used to assess the subjects' forecast accuracy. Subjects, however, are not necessarily made aware of how their forecasts affect outcomes; for the subjects the determination of actual realizations of forecasted variables often amounts to a "black-box" process. 
In a second, older experimental approach, known as the "learning to optimize experiment" (LtOE) design, subjects are asked to make economic decisions (to consume, invest, trade, produce, etc.) directly, without any elicitation of their forecasts of the relevant endogenous variables such as the market price. Of course, such forecasts can be determined implicitly based on subjects' decisions or are sometimes determined separately via some market mechanism (e.g., a double auction or a call market) that is often external to the theory being tested.

Studies using the LtFE approach find mixed evidence as to whether subjects are able to learn rational expectations (see e.g., Hommes 2011 for a survey). In some instances, subjects learn rational expectations via some adaptive learning process while in other instances subjects behave as trend extrapolators resulting in persistent deviations or cycles around the rational expectations equilibrium. Similarly, findings from LtOE studies have sometimes confirmed competitive equilibrium predictions and associated comparative statics predictions, but in other instances have generated outcomes that are at odds with RE model predictions, for instance, non-rational bubbles, excess volatility, etc.

In this paper we compare the LtFE and LtOE approaches in a common, economic decision-making task. Importantly, we also consider how behavior improves or deteriorates if we combine these two approaches. Our combined LtFE and LtOE design gets at the heart of the belief-outcome interaction that is the signature property of rational expectations models. We ask if convergence to the REE and efficiency are affected when subjects are asked to play both roles as forecaster and optimizer or if specialization of tasks by individuals alone (as in LtFE and LtOE designs) or within two-agent teams leads to a significant improvement in performance. A main aim of this research is to assess whether the results in the former LtFE literature are robust when the optimization task is performed by an individual rather than by a computer program. Moreover, the team specialization treatment that we add has a very natural, real-world interpretation: Organizational investors such as investment banks and pension funds usually employ both professional forecasters (researchers and economists) and production managers or traders.

The experimental environment we study is a simple, N-firm cobweb model economy - a negative expectation feedback system. This kind of feedback system arises naturally in commodity markets that were the inspiration for Ezekiel's (1938) devel- 
opment of the cobweb model. Furthermore, Muth (1961) proposed rational expectations in the context of this same negative feedback cobweb model. Prior research indicates that under a LtFE design, market prices will converge very quickly to the RE equilibrium in this environment. In addition to LtFE, we consider three additional treatments where the subjects need to submit their production decision directly without a forecast (LtOE), or together with a forecast, or subjects are paired in teams and one submits a forecast which the other can use to determine a production decision.

We find some tendency for the market price to converge to the RE equilibrium price in all four treatments. Thus, the stabilizing effect of a negative feedback market is a robust feature. However, when the volatility and speed of convergence are compared, we find that the market price converges most quickly and reliably when subjects only make price forecasts as in the LtFE design. There is not much difference in performance between the treatments where subjects only make production decisions (LtOE) and where they form teams that specialize in one of the two tasks. The market price and quantity fluctuate the most and are the slowest to converge when subjects are required to do both tasks, forecasting and production decision-making. Our findings have important implications for both the design of experiments and for how to think about the representative agent firm: should it be viewed as an individual actor (e.g., the C.E.O.) or is it better to think of the representative firm as consisting of teams of individuals specialized in various tasks?

The rest of the paper is organized as follows: Section 2 discusses the related literature. Section 3 describes our experimental design. Section 4 presents the experimental results. Finally, section 5 concludes.

\section{$2 \quad$ Related Literature}

Our work is related to former LtFE and LtOE studies. Smith et al. (1988), Lim et al. (1994), Arifovic (1996), Lei et al. (2001) and Crockett and Duffy (2010) are some examples of LtOE studies. Adam (2007), Marimon et al. (1993), Marimon and Sunder (1993, 1994, 1995), Hommes et al. (2005, 2007) and Heemeijer et al (2009) are some representative works in the LtFE literature. 
As we also have a treatment where subjects participate as members of teams, our experiment is related to the literature on the comparison of group and individual decisions. In the context of experimental macroeconomics and finance, Blinder and Morgan (2005) show that monetary policy decisions made by groups are not slower than those made by individuals, and are generally better; Kocher and Sutter (2005) find that groups learn faster, and can beat individuals when they are playing as opponents in Beauty-Contest Games. There is a parallel literature in experimental game theory on individual versus group decisions. The evidence is mixed on whether groups are more "rational" or self-interested than individuals. Bornstein and Yaniv (1998) find groups offer less and accept less in the ultimatum game relative to individuals. Cox (2002) shows that there is no significant difference between group and individual decisions in the trust game. Cason and Mui (1997) find that groups offer more in dictator games than indvididuals. In all of these group-versus-individual-studies, group members are asked to perform/participate in the same kind of the task, and the decision of the group is usually the average or majority choice of the group members. By contrast, our team treatment involves specialization of tasks between the two group members.

Our work is also related to the experiments on Cournot oligopoly. Offerman, Potters and Sonnemans (2002) demonstrate that giving subjects different information about other firms' behavior (information about the sum of the other firms' quantity only, about individual firm's quantity only or about individual firm's quantity and profit) can lead to different learning rules, and market evolution towards different equilibria (Walrasian, Collusive and Cournot-Nash). In our experiment, subjects have no information about other firm's quantity and profit at all. They also have no information about the relationship between the market price and total output. As the optimal quantity decision requires them to set price equal to marginal cost, the rational expectation equilibrium in this Cournot market is the same as the Walrasian outcome. Huck, Normann and Oechssler (1999) vary information available to subjects from full information about the market including others' decisions and profits and their own decision and profit to only their own decision and profit, while they still know the number of subjects in the market. They found none of the treatments generates successful collusion, and information that encourage "imitating the best" learning leads to Walrasian outcome, which confirms the prediction of Vega-Redondo (1997). Their NOIN treatment, where subjects have no information about others' 
behavior is similar to the information we provide subjects except that their subjects know the number of firms in the market. Their NOIN treatment generates an outcome very close to the Walrasian outcome and that is why we chose this informational structure for our experiment. However, as they use constant marginal cost in their paper, the optimal quantity given a price prediction is piecewise linear, and generates no steady state. It is therefore not possible to test convergence to RE equilibrium using their experimental design.

\section{Experimental Design}

\section{$3.1 \quad$ Treatments}

Our experiment consists of four treatments that differ in the tasks assigned to participants and in the payoff scheme. Sample experimental instructions are provided in the Appendix. Subjects are playing the role of firms only, deciding on price forecasts or optimal production amounts or both.

1. Treatment 1: the LtFE treatment. In this treatment, subjects (firms) only make price forecasts. Each firm's production decision is calculated by the computer optimally, given the firm's price forecast. Each subject is paid according to the accuracy of his forecast alone. The forecasters know: the history of the market price they are attempting to forecast which is standard in the LtFE literature and the history of their own forecasts and payoffs. Each subject can read his payoff from the forecasting task for different prediction errors from the payoff table (See Appendix, "Payoff Table for the Forecaster").

2. Treatment 2: the LtOE treatment. In this treatment, subjects (firms) only make quantity (or production) decisions. Each subject knows the history of the market price, his own prior decisions and profits. Each subject makes a quantity decision only; there is no elicitation of a subjects price forecast. The market price is determined by the production decisions submitted by all firms in the market. Each subject is paid according to the profit his firm makes each period. He can read his payoff for different combinations of the market price 
and his production (optmization) decisions from the payoff table (See Appendix, "Payoff Table for the Production Manager").

3. Treatment 3: the LtFE+LtOE Individual treatment. In this treatment, each subject plays the role of both forecaster and production manager. Each subject knows the history of the market price, his prior decisions and profits. Each subject makes both a price forecast and a quantity decision. The market price is determined by the quantity decisions of all firms in the market. Subjects are paid according to an equal weighted linear combination of the payoff functions used in the LtFE and LtOE treatments. Each subject can read his payoff for the forecasting task from the payoff table for forecasters, and his payoff from the production (optimization) task from the payoff for quantity decisions.

4. Treatment 4: the LtFE+LtOE Team treatment. In this treatment, there is a forecaster and a production manager in each team. The forecaster knows the history of market prices, and the production manager knows the history of his own production decisions and profits. The market price is determined by the production decisions of all firms in the market. Each subject is paid according to an equal weighted linear combination of the payoff functions used in the LtFE and LtOE treatments, exactly as in treatment 3. Subjects can read the payoff for the forecasting task from the payoff table for forecasters, and the payoff for the production task from the payoff for quantity decisions.

The price in the experiment is restricted to be non-negative, so forecasters are also not allowed to submit negative forecasts. We set 60 as the upper bound for the price prediction, because this is the maximum of the price (when all firms produce 0). The quantity decision should also be non- negative, and we set 20 as the upper bound for the quantity decision as the payoff for the production manager will be negative if he produces more than 20 units when the price is 0 .

\subsection{Number of Observations}

We report results from 8 experimental sessions that were conducted using the CREED laboratory at the University of Amsterdam on April 27-29 and on May 3, 2011. There were a total of 180 experimental subjects who participated in the 8 sessions of this 
experiment. No subject participated in more than one treatment or session. Each session involved multiple groups of $N=6$ or $N=12$ participants who interacted with one another for 50 periods in one of our four treatments, that is, we adopt a "between subjects" design. We refer to each independent observation, involving $N=6$ or 12 subjects interacting together for 50 periods under the same treatment conditions as a "market." A summary of the number of markets (observations) and the number of participants per market for each of our four treatments is given in Table 1:

\begin{tabular}{ccccc}
\hline \hline $\begin{array}{c}\text { Treatment } \\
\text { Number }\end{array}$ & $\begin{array}{c}\text { Number of Firms } \\
\text { Per Market }\end{array}$ & $\begin{array}{c}\text { Number of Participants } \\
\text { per Market }\end{array}$ & $\begin{array}{c}\text { Total Number of } \\
\text { Markets (Observations) }\end{array}$ & $\begin{array}{c}\text { Total Number } \\
\text { of Participants }\end{array}$ \\
\hline 1 & 6 & 6 & 4 & 24 \\
2 & 6 & 6 & 7 & 42 \\
3 & 6 & 6 & 7 & 42 \\
4 & 6 & 12 & 6 & 72 \\
\hline \hline
\end{tabular}

Table 1: Characteristics of the Experimental Design

Notice that in treatments 1, 2 and 3 we always had 6 subjects (or firms) per market, while in our team treatment 4 we had 12 subjects per market so that each of the 6 "firms" consisted of a pair of players (a "team") who remained matched together for all 50 rounds of the market.

\subsection{Theoretical Model}

Let $D$ be a nonnegative and monotonically decreasing demand function and let $S_{h, t}$ be the nonnegative supply function of firm $h$, derived from expected profit maximization. Let $p_{h, t}^{e}$ be the price forecast made by firm $h$ at period $t$. The supply function may be rewritten as $S\left(p_{h, t}^{e}\right)$. We assume that all firms have the same supply function. Market demand is assumed to be exogenously given in our experiment. Subjects were exclusively in the role of firms.

The market price is determined by the market clearing condition for a cobweb economy, which is given by:

$$
p_{t}=D^{-1}\left(\sum_{h} S_{h, t}\right)+\epsilon_{t}
$$

where $\epsilon_{t} \sim N(0,1)$ is the realization of an i.i.d. price shock in period $t$. 
We assume there are $H$ suppliers, only differing in the way they form expectations. We use a linear demand function $D\left(p_{t}\right)=a-b p_{t}$, where $a=63, b=\frac{21}{20}$. We assume each firm has a cost function $c(q)=\frac{H q^{2}}{2}$. The expected profit of a firm $\pi_{h, t}^{e}$ can be defined as:

$$
\pi_{h, t}^{e}=p_{h, t}^{e} q_{h, t}-c\left(q_{h, t}\right)
$$

Solving the profit maximization problem yields the optimal supply function for

each firm: $S^{*}\left(p_{h, t}^{e}\right)=\frac{p_{h, t}^{e}}{H}$. If every firm makes supply decisions optimally, the total supply on the market will coincide with the mean price forecasts, $\left(\sum_{h} S^{*}\left(p_{h, t}^{e}\right)=\overline{p_{t}^{e}}\right)$. Substituting this optimal market supply into the market clearing condition (3.3) and noting that the expected value of the noise term is zero, we have that:

$$
p_{t}=\frac{20}{21}\left(63-\overline{p_{t}^{e}}\right)
$$

Imposing the $\mathrm{RE}$ assumption, we find the rational expectations equilibrium (REE) price, $p^{*}=30.73$. The optimal supply in this REE is 5.12 , and the profit for each firm is 78.7 .

Subjects were not informed of the precise demand function as detailed in this section nor were they informed of the total quantity supplied (the quantity decisions of the other $N-1$ subjects in their market). However, they were told that market demand was decreasing in the market price and that the market price was determined by market clearing, i.e. that supply equals demand -see the Instructions in the Appendix for specific details.

\subsection{Computer Interface}

Figure 1 provides an illustration of the computer interface that subjects saw in the experiment. The screen was divided into 3 mini pages. In the top mini page, subjects were prompted to submit their decisions, i.e., their price forecast or their quantity production choice. In the bottom left mini page they saw a graph plotting past market prices (the Real Price) and, if they were a forecaster, they also saw their past price forecast history (Your Prediction). Finally, in the bottom right mini page they saw 
a table containing reporting the history of market prices, as well as their own prior decisions and their period and cumulative payoffs.

The top panel of Figure 1 shows the computer interface that forecasters saw in treatment 4 . The computer interface the forecasters saw in treatment 1 is very similar to the one shown for forecasters in treatment 4, except that the history of past performance (points earned) was only for the forecasting task and not from the optimizing task as in treatment 4.

The bottom panel of Figure 1 shows the computer interface the production managers saw in treatment 4 . At the start of each period these production managers were told "We wait for your partner to give a forecast." Once the forecaster/team partner has submitted his/her forecast, the production manager was informed of this forecast (as show in the bottom panel of Figure 1) and he or she then entered a quantity decision for the team. The computer interface that subjects see in treatment 2 is very similar to that shown in the bottom panel of Figure 1 except that there is no waiting phase, and the history of past performance is only for the optimization task instead of for both the forecasting and optimization tasks as in treatment 4 . The computer interface in treatment 3 is also similar to the one shown in Figure 1, except that there is no waiting phase, and the same subject is asked to first submit a price forecast and then to submit a quantity decision. The history of past performance for treatment 3 is the same as for treatment 4 as the payoff functions are the same in these two treatments.

We note that there were no time constraints on decision-making in any of our treatments. The market price was not determined until all $N$ subjects had submitted their price forecasts and/or quantity production decisions. Each round took no more than 3 minutes to complete (and was often much faster than that).

\subsection{Payoffs}

Subjects earned points during the experiment that were converted into Euros at the end of the experiment at a known and fixed rate. The payoff function for forecasters is a decreasing function of their prediction error, and was given by:

$$
\text { Payoff for Forecasting Task }=\max \left\{1300-\frac{1300}{49}\left(p_{t}-p_{h, t}^{e}\right)^{2}, 0\right\}
$$




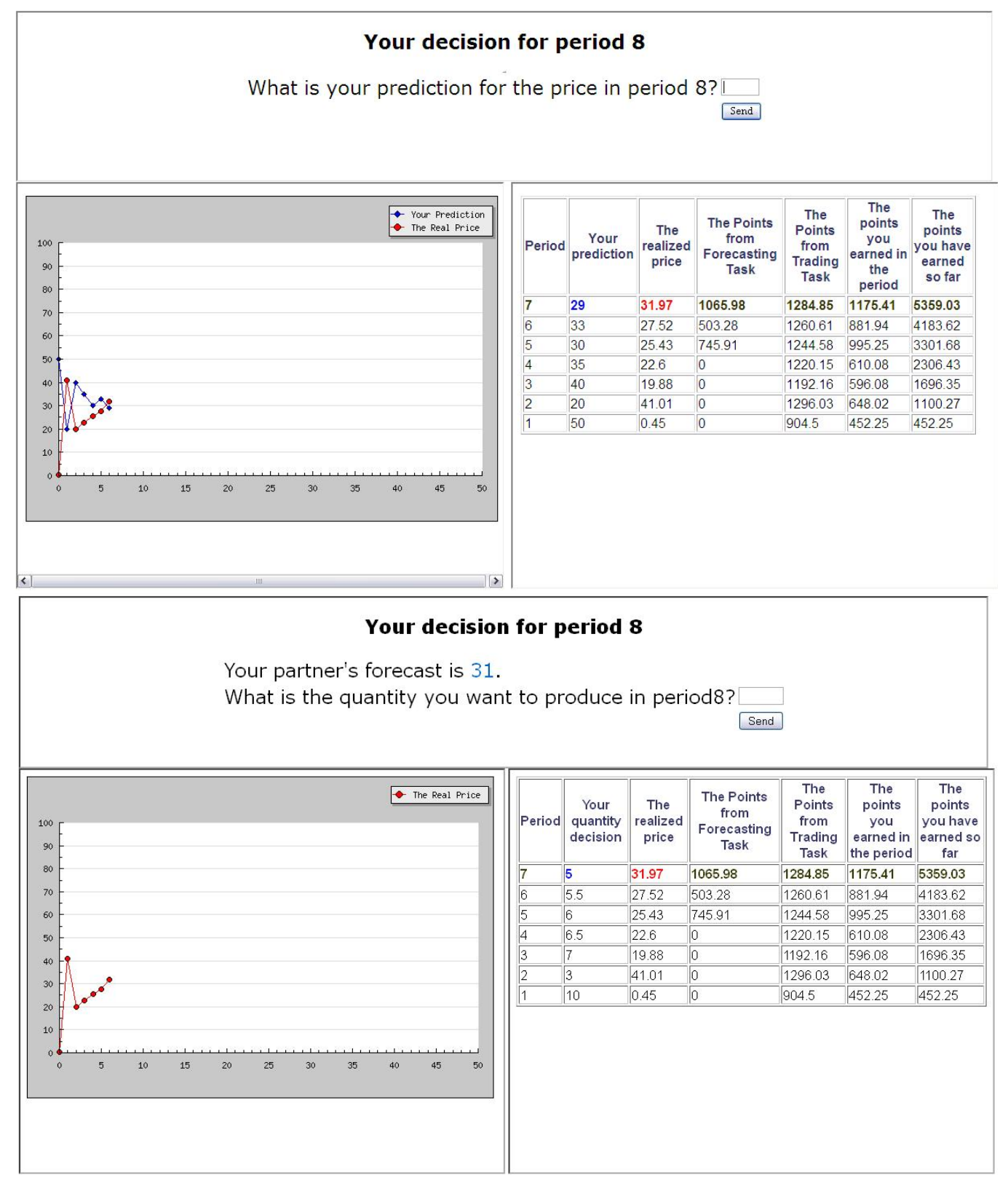

Figure 1: The computer interface for forecasters (top) and production managers (bottom). 
Notice that subjects earn 0 if their price forecast error is greater than 7 .

The payoff function for the production (optimization) task was given by:

$$
\text { Payoff from the Production Task }=p_{t} q_{t}-c\left(q_{t}\right)+1200
$$

Notice that subjects get a 1200 baseline salary, plus the actual profit earned by their firm, which depends on the market determined price, $p_{t}$ and on the quantity, $q_{t}$, chosen by their firm. A firm's profit can be negative, so a subject's payoff can be smaller than 1200. However, we make sure that the maximum loss (the absolute value of negative profit) is 1200 , so that each subject's total payoff can never be negative. As the profit for the firm when the market price is at the REE prediction is about 80, the maximum payoff earned by a subject as a forecaster or as a production manager is approximately the same, at around 1300 points.

Subjects in treatment 1 earn the payoff from the forecasting task only. Subjects in treatment 2 earn the payoff from the production task only. Subjects in treatments 3 and 4 each earn the equal weighted average of the payoffs from the forecasting and production tasks. These payoff functions were carefully explained to subjects in the written instructions and presented to subjects as Tables (see the Appendix). At the end of the experiment, subjects were paid 1 Euro for each 2600 points they earned in all 50 rounds of the experiment.

\section{Experimental Results}

\subsection{Aggregate Market Price}

Figure 1 plots the average market prices in each treatment against the REE price, $p^{*}=$ 30.73. We see that the average price in all four treatments tracks the fundamental price very well, especially in the later periods of the experiment. So the general tendency for a negative feedback market to converge to REE is not affected too much by the type of task assigned to the market participants. However, the adjustment towards REE at the beginning of the experiment is fastest in treatment 1 and is slowest in treatment 3 . The volatility of the market price is also smallest in treatment 1 , and largest in treatment 3. 

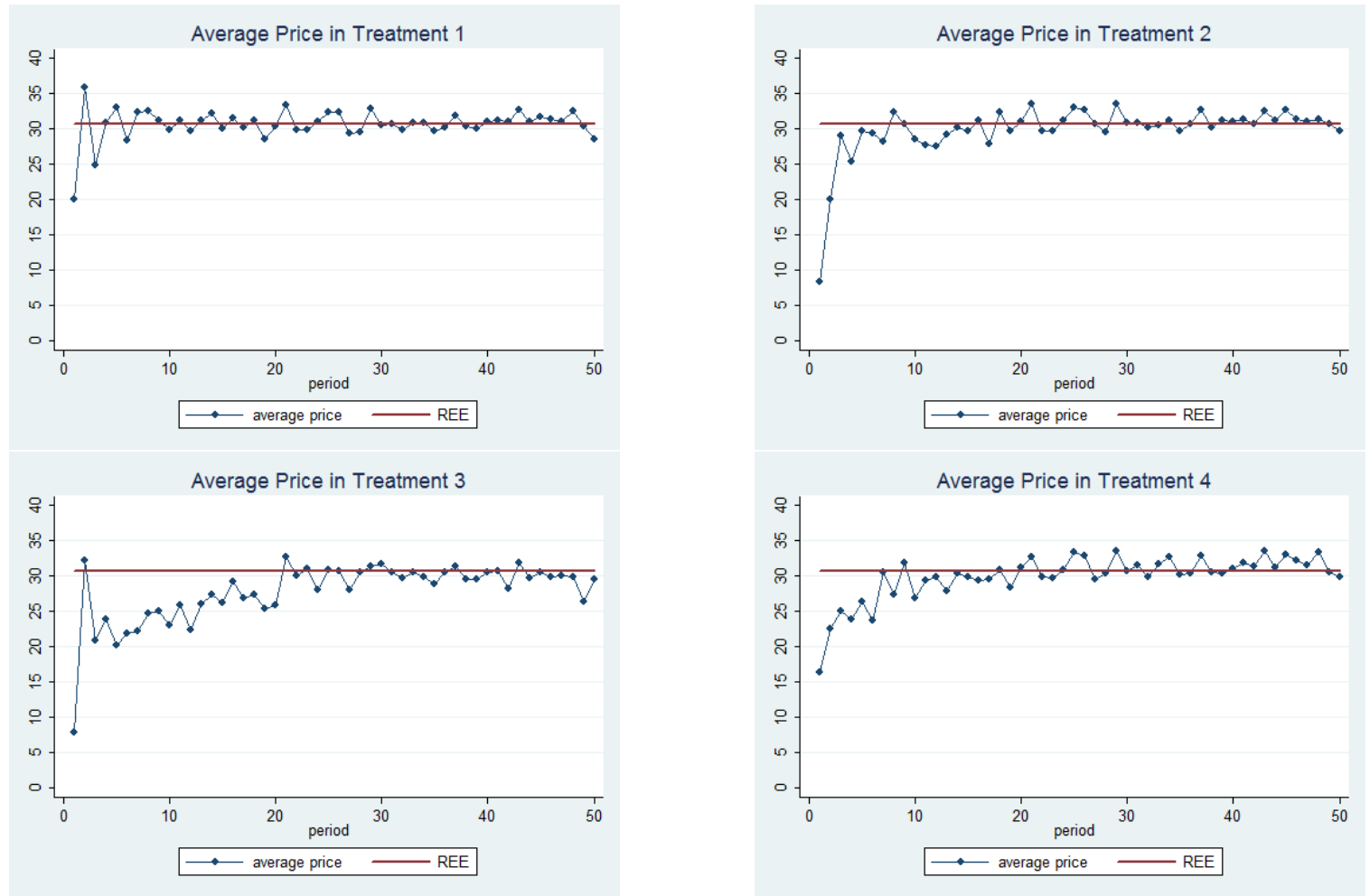

Figure 2: The average market price against the REE price in each of the four treatments. 
As a first check on whether prices are converging to the RE prediction, we declare convergence to have occurred in the first period for which the difference between the market price and the REE price is less than 5 and stays below 5 forever after that period. We count the number of periods before convergence in the markets of the different treatments, as reported in Table 2. If there is no convergence according to our criterion, as is the case for 5 markets in treatment 3, then we count the number of periods to convergence as the full sample size of 50 periods. By comparing these numbers, we can see the market price converges faster in treatment 1 than in the other three treatments (the difference is significant at the $5 \%$ level according to a Wilcoxon Mann Whitney test using the independent market observations for each treatment). The convergence is faster in treatments 2 and 4 than in treatment 3 (the difference is significant at the $5 \%$ level according to a Wilcoxon Mann Whitney test). Treatment 4 converges slightly faster than treatment 2 on average, but that difference is not significant at $5 \%$ level according to Wilcoxon Mann Whitney test.

For a second view of convergence, Figure 3 plot the average difference between the market price and the REE price using data from all markets of each treatment.

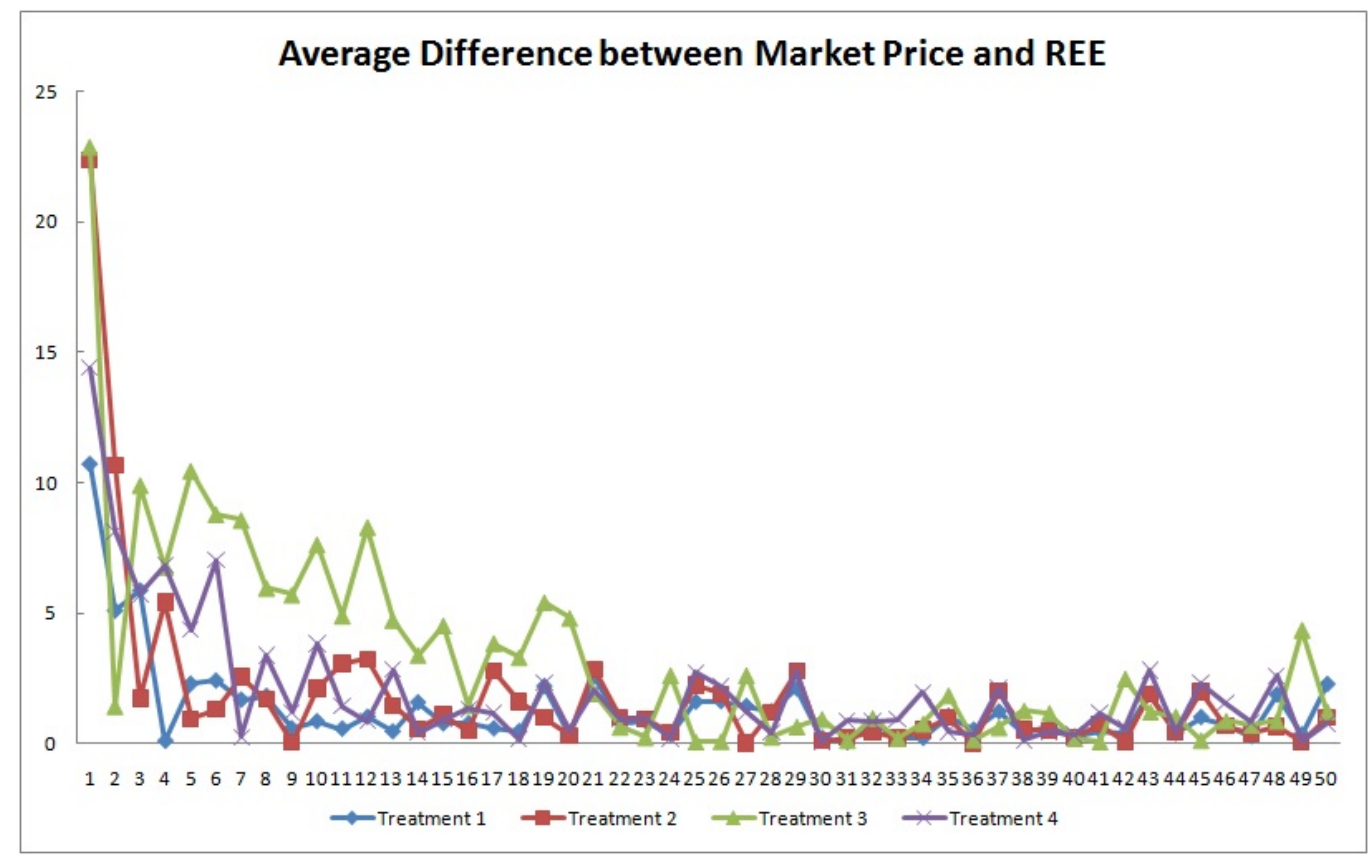

Figure 3: The distance between the fundamental price and the average of the market prices from all markets of each treatment.

Figure 3 reveals that the difference decreases most rapidly toward zero in treat- 


\begin{tabular}{|c|c|c|}
\hline Treatment & Market & Number of Periods before Convergence \\
\hline \multirow[t]{6}{*}{ Treatment 1} & Market 1 & 3 \\
\hline & Market 2 & 3 \\
\hline & Market 3 & 4 \\
\hline & Market 4 & 1 \\
\hline & Mean & 2.75 \\
\hline & Median & 3 \\
\hline \multirow[t]{9}{*}{ Treatment 2} & Market 1 & 17 \\
\hline & Market 2 & 33 \\
\hline & Market 3 & 13 \\
\hline & Market 4 & 12 \\
\hline & Market 5 & 11 \\
\hline & Market 6 & 4 \\
\hline & Market 7 & 28 \\
\hline & Mean & 14.43 \\
\hline & Median & 13 \\
\hline \multirow[t]{9}{*}{ Treatment 3} & Market 1 & 50 \\
\hline & Market 2 & 50 \\
\hline & Market 3 & 35 \\
\hline & Market 4 & 3 \\
\hline & Market 5 & 50 \\
\hline & Market 6 & 50 \\
\hline & Market 7 & 50 \\
\hline & Mean & 42.29 \\
\hline & Median & 50 \\
\hline \multirow[t]{8}{*}{ Treatment 4} & Market 1 & 36 \\
\hline & Market 2 & 10 \\
\hline & Market 3 & 13 \\
\hline & Market 4 & 25 \\
\hline & Market 5 & 6 \\
\hline & Market 6 & 10 \\
\hline & Mean & 10.67 \\
\hline & Median & 10 \\
\hline
\end{tabular}

Table 2: The number of periods before convergence for each market. 
ment 1 (circles), and most slowly in treatment 3 (triangles). Treatment 2 (squares) and treatment 4 are very similar to one another.

Finally we can test for convergence econometrically using a method suggested by Duffy (2008). The following linear equation is estimated:

$$
p_{j, t}=\lambda_{j} p_{j, t-1}+\mu_{j}+\epsilon_{j, t}
$$

This linear equation is stable if $\lambda$ is smaller than 1 , and has a long term equilibrium level $\frac{\hat{\mu}_{j}}{1-\hat{\lambda}_{j}}$. For a market $j$, we declare a weak convergence if reject $\hat{\lambda}_{j} \geq 1$ at $5 \%$ level, and a strong convergence if we can not reject $\frac{\hat{\mu}_{j}}{1-\hat{\lambda}_{j}}=30.73$ at $5 \%$ level. The estimation results are shown in the appendix. We see from the results that:

1. All markets in all the treatments satisfy weak convergence.

2. All markets in treatment 1 and 2 satisfy strong convergence. All but one market in treatment 4 satisfy strong convergence. The equilibrium price in the one market of Treatment 4 that does not satisfy strong convergence is not very different from the REE $\left(\frac{\hat{\mu}_{j}}{1-\hat{\lambda}_{j}}=32.08\right)$. Only 2 out of 7 markets in treatment 3 satisfy strong convergence.

We see a large difference between treatment 3 and the other three treatments. The difference between treatments 3 and 4 in particular suggests that teamwork and specialization may help participants to make optimal decisions.

\subsection{Individual-Level Decisions}

We have seen that aggregate market price tracks the REE well in many markets. It is of interest to consider whether decisions at the individual level are also consistent with RE predictions. The empirical cumulative distribution function (CDF) of individual forecasts and optimization decisions is shown in Figure 4 using pooled data from all markets of the various treatments. Under rational expectation the CDF should be a step function switching from 0 to 1 at the RE price or quantity.

Figure 4 reveals that there is some heterogeneity in individual decisions across treatments with the largest departures from RE predictions occurring in treatment 3 , 

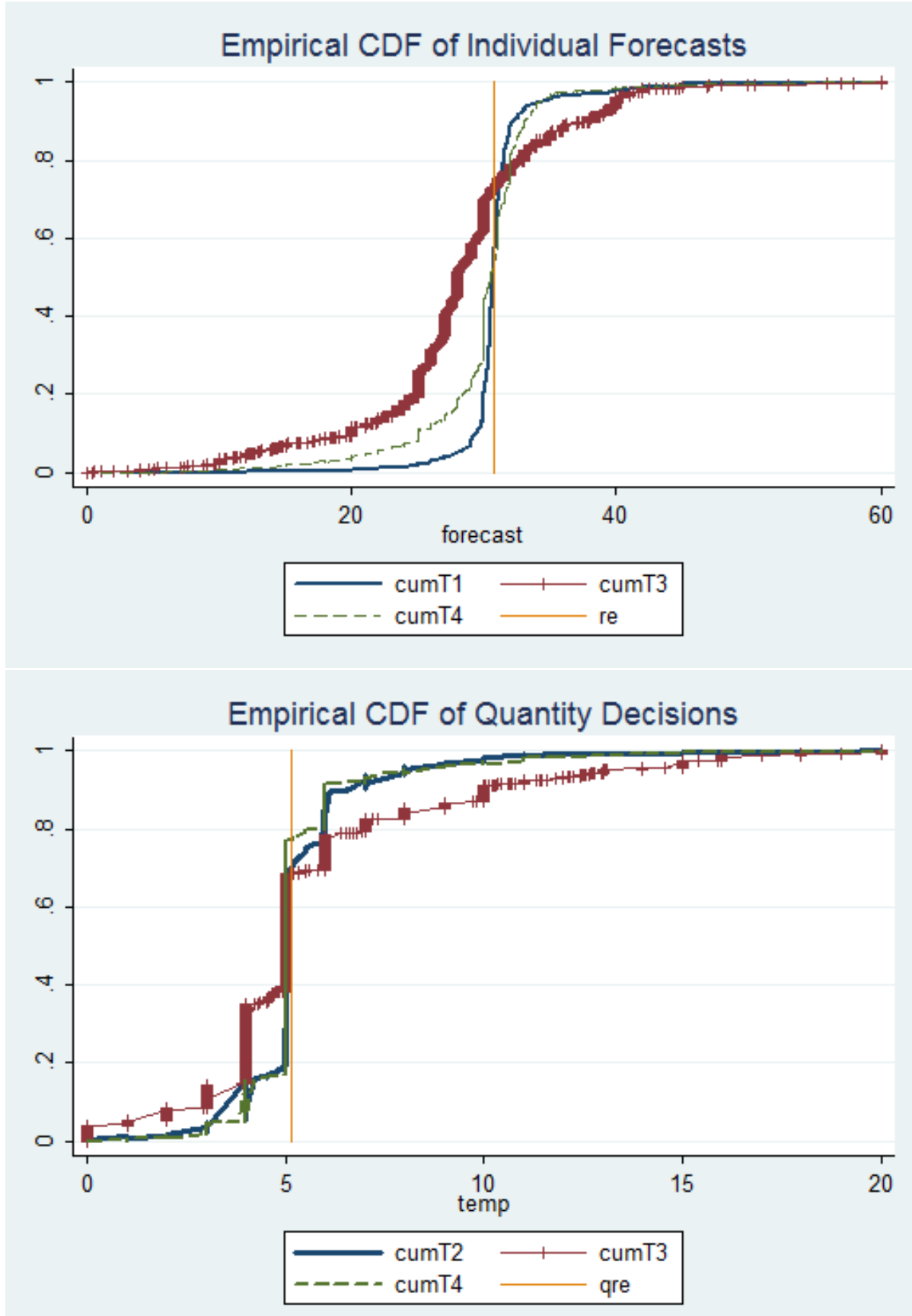

Figure 4: The empirical cdf of individual forecasting and quantity decisions. 
a finding that is consistent with our findings using aggregate measures of prices and quantities.

Using the distribution of individual forecasts for the three treatments involving forecasting, we perform a one-sample Kolmogorov-Smirnov test of whether the distribution of individual forecasts is significantly different from the RE prediction, $p^{*}=30.73$ (at the $5 \%$ level). We can reject the null hypothesis of no difference for all three treatments. The top panel of Figure 4 suggests that the distribution of individual forecasts is similar in treatments 1 and 4 , while treatment 3 looks very different. For confirmation we perform a two-sample Kolmogorov-Smirnov test on whether the distribution of individual forecasts is the same between each of pairing of these three treatments, and we find that each treatment is significantly different from the others (at 5\% level). Indeed, the ordering is such that Treatment 1 is closest to the RE price prediction, treatment 3 is furthest and treatment 4 is intermediate.

For the distribution of individual quantity decisions, we also perform a one-sample Kolmogorov-Smirnov test on whether the distribution of individual quantity decisions is significantly different from the RE prediction that all firms produce 5.12 units (at $5 \%$ level). We can again reject the null hypothesis of no difference for all three treatments involving quantity decisions. The lower panel of Figure 4 suggests that the distribution of individual quantity decisions is similar in treatments 2 and 4 , while treatment 3 looks very different. We again perform a two-sample KolmogorovSmirnov test on whether the distribution of individual quantity decisions is the same between each pairing of the three treatments. The test indicate that there is no significant difference in the distribution of quantity decisions between treatments 2 and 4 , and but there is a significant difference between treatment 3 and the other two treatments (at $5 \%$ level). In particular, there is much greater heterogeneity in the quantity decisions of treatment 3 as compared with either treatments 2 and 4 .

\subsection{Variance of the Market Price and M.S.D from REE}

The variance of the market price and the mean squared deviation (M.S.D.) of prices from the REE in our experiment are shown in Table 3. We calculate these numbers for the whole experiment and the first and second 25 periods. Both measures follow the same order: Treatment $3>$ Treatment $2>$ Treatment $4>$ Treatment 1 , although 
the difference between Treatments 1,2 and 4 are very small in the second 25 periods, when the markets in these three treatments have converged to REE. This finding basically confirms our conjecture that "two heads are better than one" (in finding the REE). Treatment 3 generates the largest variance and deviance from REE probably because subjects are a little overloaded by the need to complete two tasks at the same time. Treatment 4 improves upon Treatment 3 because specialization promotes efficiency. Treatment 4 not only yields more frequent convergence to REE but it also takes no more time to complete compared with sessions of Treatment 3: a Treatment 4 session took between 1 hour and 20 minutes to 2 hours to complete while the two Treatment 3 sessions took 1 hour and 40 minutes and 2 hours, respectively, to complete.

\begin{tabular}{|c|c|c|c|c|c|c|c|}
\hline \multirow[t]{2}{*}{ Treatment } & \multirow[t]{2}{*}{ Market } & \multicolumn{2}{|c|}{ Period 1-50 } & \multicolumn{2}{|c|}{ Period 1-25 } & \multicolumn{2}{|c|}{ Period 26-50 } \\
\hline & & Variance & MSD from REE & Variance & MSD from REE & Variance & MSD from REE \\
\hline \multirow[t]{5}{*}{ Treatment 1} & Market 1 & 8.4639 & 8.3246 & 15.9253 & 15.498 & 1.1862 & 1.1512 \\
\hline & Market 2 & 4.5009 & 4.4123 & 8.0549 & 7.7576 & 1.1042 & 1.0669 \\
\hline & Market 3 & 6.0093 & 5.8903 & 10.5023 & 10.2533 & 1.4662 & 1.5273 \\
\hline & Market 4 & 4.0495 & 3.9687 & 5.9651 & 5.7271 & 2.2995 & 2.2104 \\
\hline & Average & 5.7559 & 5.649 & 10.1119 & 9.809 & 1.514 & 1.489 \\
\hline \multirow[t]{8}{*}{ Treatment 2} & Market 1 & 37.4148 & 42.1834 & 57.3784 & 80.1954 & 4.2428 & 4.1714 \\
\hline & Market 2 & 43.1768 & 47.091 & 75.7162 & 88.4803 & 5.7746 & 5.7017 \\
\hline & Market 3 & 6.2406 & 6.3842 & 9.6834 & 9.4855 & 3.0436 & 3.2829 \\
\hline & Market 4 & 30.6806 & 30.3493 & 49.8641 & 54.9473 & 3.3323 & 5.7514 \\
\hline & Market 5 & 24.5577 & 24.3453 & 44.5447 & 44.7759 & 3.9408 & 3.9148 \\
\hline & Market 6 & 21.3695 & 20.9732 & 40.6862 & 39.4943 & 1.4866 & 2.4521 \\
\hline & Market 7 & 11.9966 & 11.7587 & 19.3881 & 18.9612 & 4.2627 & 4.5562 \\
\hline & Average & 28.9441 & 31.8862 & 47.5927 & 59.387 & 4.3537 & 4.3853 \\
\hline \multirow[t]{8}{*}{ Treatment 3} & Market 1 & 26.1905 & 27.9131 & 39.5377 & 38.5528 & 12.8353 & 17.2734 \\
\hline & Market 2 & 48.9827 & 65.194 & 54.7201 & 53.7902 & 26.2326 & 76.5979 \\
\hline & Market 3 & 76.5335 & 125.0443 & 117.0166 & 236.1772 & 4.9931 & 13.9114 \\
\hline & Market 4 & 26.9917 & 29.4857 & 51.0947 & 57.3338 & 1.3238 & 1.6376 \\
\hline & Market 5 & 20.3711 & 48.2724 & 24.2351 & 74.8411 & 10.1406 & 21.7038 \\
\hline & Market 6 & 6.9515 & 15.6452 & 12.1408 & 19.9058 & 2.0312 & 11.3847 \\
\hline & Market 7 & 60.2049 & 147.2105 & 63.8626 & 271.2218 & 4.9447 & 23.1991 \\
\hline & Average & 44.6746 & 61.9093 & 65.5922 & 96.4635 & 11.3462 & 27.3551 \\
\hline \multirow[t]{7}{*}{ Treatment 4} & Market 1 & 14.3269 & 15.3855 & 23.0514 & 22.1382 & 3.8329 & 8.6329 \\
\hline & Market 2 & 17.2713 & 17.2323 & 30.9771 & 32.2878 & 2.0178 & 2.1768 \\
\hline & Market 3 & 18.4874 & 19.2729 & 25.9906 & 32.3755 & 6.0827 & 6.1703 \\
\hline & Market 4 & 36.5533 & 40.4508 & 61.4327 & 78.6819 & 2.2928 & 2.2197 \\
\hline & Market 5 & 9.0801 & 9.92666 & 13.8618 & 18.0667 & 1.8365 & 1.7866 \\
\hline & Market 6 & 28.9092 & 29.3816 & 45.1668 & 27.1176 & 3.1776 & 3.8889 \\
\hline & Average & 20.7714 & 21.9416 & 33.4134 & 35.1113 & 3.2067 & 4.1459 \\
\hline
\end{tabular}

Table 3: The MSD from REE and variance of price for each market.

\subsection{Efficiency}

We compare subjects' earnings in the experiment to the hypothetical case where all subjects play according to the REE predictions in all 50 periods. Subjects can earn 1300 points per period for the forecasting task when they play according to REE because they make no prediction errors, which means they earn 0.5 Euro each period, 
and 25 Euros for all 50 periods. The profits they can earn for the production task is 1278.7 points per period when they play according to the REE, which means they earn 0.4918 Euro per period, and 24.59 Euros for 50 periods. We use the ratio of actual to hypothetical REE payoffs as a measure of efficiency. This measure can be greater than 100 percent in treatments with production decisions, because subjects can earn more by producing a little less than the REE prediction. These efficiency ratios reported in Table 4 are generally very high (more than 80\%) in all four treatments. We see the ranking of efficiency level in all 50 periods is Treatment $2>$ Treamtnet $4>$ Treament $1>$ Treatment 3 , the ranking in the second 25 periods is Treatment $2>$ Treatment $1>$ Treatment $4>$ Treamemt 3 . Only the difference between efficiency in treatment 2 and other treatments is significant at $5 \%$ level according to Wilcoxon Mann Whitney test. The differences between the efficiency level in other treatments are not significant.

\begin{tabular}{|c|c|c|c|c|c|c|c|}
\hline \multirow[b]{2}{*}{ Treatment } & \multirow[b]{2}{*}{ Market } & \multicolumn{2}{|c|}{ Period 1-50 } & \multicolumn{2}{|c|}{ Period 1-25 } & \multicolumn{2}{|c|}{ Period 26-50 } \\
\hline & & average earning & efficiency & average earning & efficiency & average earning & efficiency \\
\hline \multirow[t]{5}{*}{ Treatment 1} & Market 1 & 20.44 & $89.27 \%$ & 8.45 & $67.58 \%$ & 11.99 & $95.94 \%$ \\
\hline & Market 2 & 21.57 & $86.27 \%$ & 9.47 & $75.79 \%$ & 12.09 & $96.74 \%$ \\
\hline & Market 3 & 21.50 & $86.00 \%$ & 9.59 & $76.69 \%$ & 11.91 & $95.31 \%$ \\
\hline & Market 4 & 21.83 & $87.33 \%$ & 10.50 & $84.03 \%$ & 11.33 & $90.64 \%$ \\
\hline & Average & 21.80 & $87.22 \%$ & 9.50 & $76.02 \%$ & 12.30 & $98.41 \%$ \\
\hline \multirow[t]{8}{*}{ Treatment 2} & Market 1 & 24.45 & $99.43 \%$ & 11.64 & $94.70 \%$ & 12.81 & $104.16 \%$ \\
\hline & Market 2 & 23.98 & $97.53 \%$ & 11.73 & $95.43 \%$ & 12.25 & $99.64 \%$ \\
\hline & Market 3 & 23.95 & $97.40 \%$ & 12.19 & $99.18 \%$ & 11.76 & $95.61 \%$ \\
\hline & Market 4 & 24.47 & $99.50 \%$ & 11.90 & $96.81 \%$ & 12.56 & $102.19 \%$ \\
\hline & Market 5 & 24.43 & $99.36 \%$ & 12.03 & $97.85 \%$ & 12.40 & $100.88 \%$ \\
\hline & Market 6 & 24.33 & $98.96 \%$ & 12.09 & $98.35 \%$ & 12.24 & $99.56 \%$ \\
\hline & Market 7 & 24.25 & $98.62 \%$ & 12.14 & $98.71 \%$ & 12.11 & $98.53 \%$ \\
\hline & Average & 24.27 & $98.69 \%$ & 11.96 & $97.29 \%$ & 12.30 & $100.08 \%$ \\
\hline \multirow[t]{8}{*}{ Treatment 3} & Market 1 & 22.10 & $89.11 \%$ & 9.68 & $78.07 \%$ & 12.42 & $100.16 \%$ \\
\hline & Market 2 & 18.57 & $74.87 \%$ & 9.42 & $75.96 \%$ & 9.15 & $73.78 \%$ \\
\hline & Market 3 & 20.63 & $83.20 \%$ & 7.08 & $57.07 \%$ & 13.56 & $109.33 \%$ \\
\hline & Market 4 & 21.18 & $85.42 \%$ & 10.53 & $84.93 \%$ & 10.65 & $85.91 \%$ \\
\hline & Market 5 & 19.12 & $77.08 \%$ & 9.06 & $73.04 \%$ & 10.06 & $81.13 \%$ \\
\hline & Market 6 & 22.78 & $91.87 \%$ & 10.93 & $88.16 \%$ & 11.85 & $95.58 \%$ \\
\hline & Market 7 & 19.27 & $77.69 \%$ & 8.39 & $67.67 \%$ & 10.88 & $87.71 \%$ \\
\hline & Average & 20.52 & $82.75 \%$ & 9.30 & $74.98 \%$ & 11.22 & $90.51 \%$ \\
\hline \multirow[t]{7}{*}{ Treatment 4} & Market 1 & 22.10 & $89.11 \%$ & 10.07 & $81.22 \%$ & 12.03 & $97.00 \%$ \\
\hline & Market 2 & 21.80 & $87.90 \%$ & 10.14 & $81.81 \%$ & 11.66 & $93.99 \%$ \\
\hline & Market 3 & 21.08 & $85.01 \%$ & 9.36 & $75.48 \%$ & 11.72 & $94.55 \%$ \\
\hline & Market 4 & 20.60 & $83.06 \%$ & 9.16 & $73.83 \%$ & 11.44 & $92.30 \%$ \\
\hline & Market 5 & 22.32 & $89.99 \%$ & 10.09 & $81.38 \%$ & 12.23 & $98.60 \%$ \\
\hline & Market 6 & 22.13 & $89.25 \%$ & 10.65 & $85.85 \%$ & 11.49 & $92.64 \%$ \\
\hline & Average & 21.67 & $87.39 \%$ & 9.91 & $79.93 \%$ & 11.76 & $94.85 \%$ \\
\hline
\end{tabular}

Table 4: The efficiency for each market.

However, as the payoff functions for the forecasting and optimizing tasks were different, it is difficult to draw conclusions from the reported efficiency ratios across some of the treatments. One way to make the results more comparable is to examine implicit production decisions in treatment 1 and implicit price forecasts in treatment 2 , and then calculate the implicit efficiency level of the production decisions in treat- 
ment 1, or the implicit efficiency of forecasting task in treatment 2. For treatment 1, it is straightforward that the firm will produce as much as one sixth of the prediction, and the profit of the firm can be calculated accordingly. For treatment 2, we can assume that the subjects always make production decisions that are conditionally optimal for their implicit forecast, and therefore we calculate their implicit forecast as six times their quantity decision. Given these numbers we can calculate the efficiency level for both the forecasting and optimizing tasks for all four treatments in a consistent manner and we can define an efficiency index for all the treatments as the mean of the efficiency levels for the two tasks. This index, which allows for efficiency comparisons across the four treatments, is reported in Table 5.

Table 5 reveals that efficiency level for the implicit optimizing task in treatment 1 is as high as the comparable efficiency level of the optimizing task in treatment 2 , and sometimes exceeds $100 \%$ in the second 25 rounds of the experiment. This suggests that the higher efficiency level reported for treatment 2 as compared with treatment 1 may be an artifact of the payoff function differences. Subjects performing the optimization task benefit from small, positive random shocks which result in higher market price. By contrast, both positive and negative shocks are equally penalizing for subjects performing the prediction task as both types of shocks lead to higher prediction errors.

Table 5 also reveals that the ranking of the overall efficiency index is Treatment $1>$ Treatment $4>$ Treatment $3>$ Treatment2. This ranking for the forecasting task is the same as the overall ranking, and the ranking for the optimizing task is Treatment $1>$ Treatment $2>$ Treatment $4>$ Treatment 3 . We conducted a Wilcoxon Mann Whitney test on market level efficiency for the two tasks and on the efficiency index for period 1-50. The result suggests that the efficiency level is significantly higher in treatment 1 in both tasks as well as for the efficiency index as compared with all other treatments. The efficiency for forecasting is significantly lower in treatment 2 as compared with the other treatments ${ }^{1}$, but there are no other significant difference in pairwise comparisons between treatments. As we will see in later sections, subjects in treatments 3 and 4 (especially treatment 3 ) do not make perfect production decisions given their forecasts. This result suggests that it does not cause a lot of

\footnotetext{
${ }^{1}$ This result may be due to our assumption that the implicit forecast is 6 times the quantity , or the fact that the subjects do not act conditionally optimally to their implicit forecast (produce exactly one sixth of the implicit forecast).
} 
differences in the efficiency if subjects are boundedly rational in optimization tasks. But if subjects are not fully rational with regard to the optimization task, this may lead to inaccurate forecasts as well resulting in lower forecast efficiency.

This result also suggests that caution needs to be taken in explaining a high efficiency level in learning to optimize experiments, because even if the efficiency says there is no problem in the optimization task, the implicit forecasts made by the subjects may be far from rational. In this case, the team design with specialized roles provides a clearer view of the decision process in each task, and restores the efficiency level in forecasting.

\begin{tabular}{|c|c|c|c|c|c|c|}
\hline Treatment & Periods & Avg. Payoff Forecasting & Avg. Payoff Optimizing & Efficiency Forecasting & Efficiency Optimization & Efficiency Index \\
\hline \multirow[t]{3}{*}{ Treatment 1} & Period $1-50$ & 21.80 & 24.55 & $87.22 \%$ & $99.85 \%$ & $93.54 \%$ \\
\hline & Period 1-25 & 9.50 & 12.26 & $76.02 \%$ & $99.68 \%$ & $87.85 \%$ \\
\hline & Period 26-50 & 11.99 & 12.30 & $98.41 \%$ & $100.03 \%$ & $99.22 \%$ \\
\hline \multirow[t]{3}{*}{ Treatment 2} & Period 1-50 & 14.45 & 24.27 & $57.79 \%$ & $98.69 \%$ & $78.24 \%$ \\
\hline & Period 1-25 & 5.78 & 11.96 & $46.24 \%$ & $97.29 \%$ & $71.76 \%$ \\
\hline & Period 26-50 & 8.67 & 12.30 & $69.36 \%$ & $100.08 \%$ & $88.68 \%$ \\
\hline \multirow[t]{3}{*}{ Treatment 3} & Period 1-50 & 17.63 & 23.39 & $70.53 \%$ & $95.14 \%$ & $82.84 \%$ \\
\hline & Period 1-25 & 7.19 & 11.41 & $57.48 \%$ & $92.81 \%$ & $75.15 \%$ \\
\hline & Period 26-50 & 10.45 & 11.98 & $83.57 \%$ & $97.47 \%$ & $90.52 \%$ \\
\hline \multirow[t]{3}{*}{ Treatment 4} & Period 1-50 & 19.08 & 24.27 & $76.31 \%$ & $98.68 \%$ & $87.50 \%$ \\
\hline & Period 1-25 & 7.87 & 11.96 & $62.93 \%$ & $97.24 \%$ & $80.09 \%$ \\
\hline & Period 26-50 & 11.21 & 12.31 & $89.69 \%$ & $100.12 \%$ & $94.91 \%$ \\
\hline
\end{tabular}

Table 5: The breakdown of efficiency into forecasting and optimizing tasks.

\subsection{Individual Forecast}

The left panel of Figure 5 shows the average individual price forecasts in treatments 1, 3 and 4 against the REE. We can see that Treatment 1 converges fastest, followed by treatment 4 , and that treatment 3 is the slowest to converge. The right panel of Figure 5 shows the average variance of individual forecasts in treatments 1, 3 and 4. We observe that heterogeneity of supply decisions is greatest in treatment 3 , and there is not much difference between treatments 1 and 4 .

Prior experimental work (Heemeijer et al, 2009) suggests that subjects tend to use simple heuristics in learning to forecast experiments. Two natural candidates they often use in negative feedback markets are adaptive expectations:

$$
p_{i, t+1}^{e}=p_{i, t}^{e}+\lambda\left(p_{t}-p_{i, t}^{e}\right)
$$



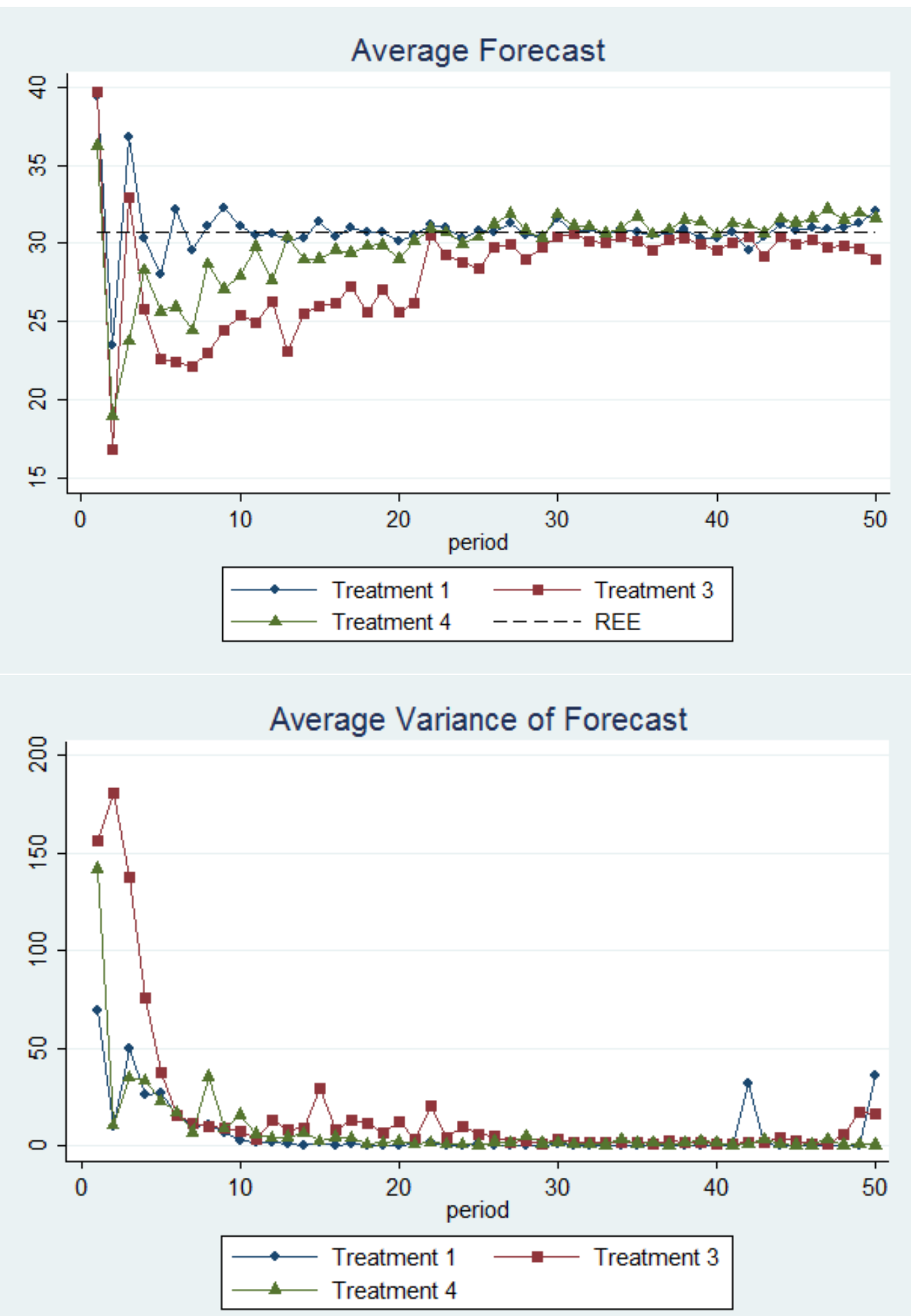

Figure 5: The upper panel shows the average individual forecasts in Treatment 1, 3 and 4 . The bottom panel shows the average of the group variance of individual forecasts in Treatments 1, 3 and 4. 
and trend extrapolation rules:

$$
p_{i, t+1}^{e}=p_{t}+\gamma\left(p_{t}-p_{t-1}\right)
$$

The estimated $\gamma$ is usually negative in the market setting we consider, so we use the term "contrarian rule" to differentiate this rule from the trend-following rule where $\gamma$ is positive. We estimate these two types of rules. We examine the estimation results after performing the estimation. We call an estimation successful if it generates coefficient estimates that are significant at the $5 \%$ level, and there is no serial correlation. If both rules are successful for the same individual, we compare the $R^{2}$ of each estimated model and characterize the individual as following the rule with larger $R^{2}$. It turns out that more than $75 \%$ of subjects can be categorized by either rule in all treatments. The distribution of individual subjects over the types of forecasting rules is shown in Table 6 and Figure 6, while the Tables in Appendix B show the estimation results for the subjects who can be successfully identified with one rule:

\begin{tabular}{cccc}
\hline Treatment & Adaptive & Contrarian & Neither \\
\hline Treatment 1 & $66.67 \%$ & $12.50 \%$ & $20.83 \%$ \\
Treatment 3 & $52.38 \%$ & $23.81 \%$ & $23.81 \%$ \\
Treatment 4 & $50.00 \%$ & $27.78 \%$ & $22.22 \%$ \\
\hline
\end{tabular}

Table 6: The fraction of subjects who are characterized by one type of forecasting rule or neither.

Generally speaking, the distribution of subjects over the different rules is not very different across the three treatments. In all three treatments $50 \%$ or more subjects can be categorized by the adaptive rule. There are relatively more subjects using the contrarian rule in Treatments 3 and 4 as compared with Treatment 1 . If we relate the result here to the stability of the markets, it seems the market price is most stable when there are overwhelmingly more people using the adaptive rule.

\subsection{Individual Supply Decision}

\subsubsection{Descriptive Statistics}

The average supplies in treatment 2, 3 and 4 are plotted against the REE supply in the top panel of Figure 7 . As with prices, we see that quantity in treatment 3 

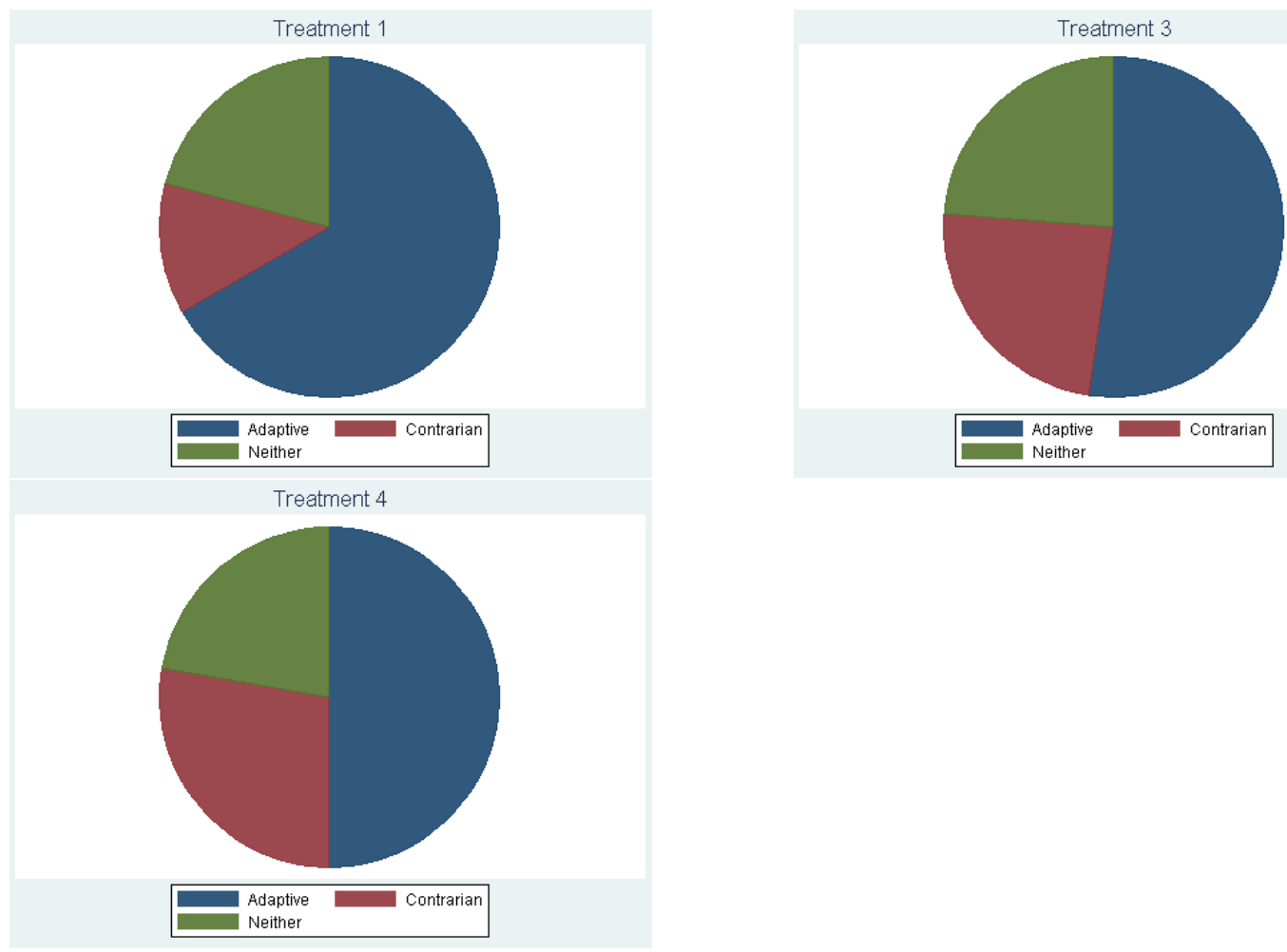

Figure 6: The fraction of subjects who are characterized by one type of forecasting rule or neither in treatment 1 (top left), 3 (top right) and 4 (bottom). 

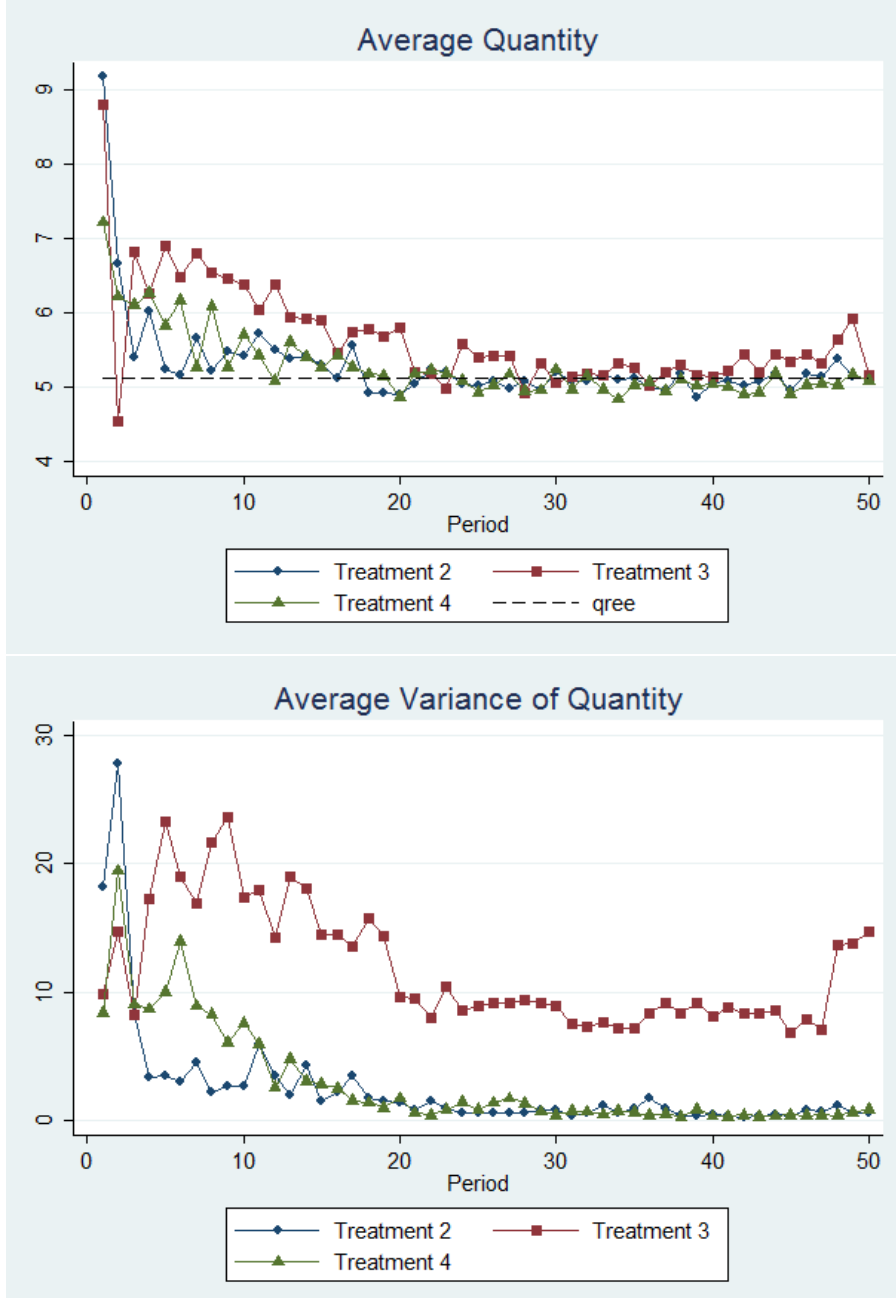

Figure 7: Upper panel: the average individual supply in Treatments 1, 3 and 4. Bottom panel: the average variance of individual supply in Treatments 1, 3 and 4 . 
converges towards the REE level in a rather sluggish manner, and there is not much difference in the average quantity supplied over time between treatments 2 and 4 . The bottom panel of Figure 7 shows the average variance of supply in each treatment. We again observe that the heterogeneity of supply decisions is greatest in treatment 3, and there is not much difference between treatments 2 and 4 .

\subsubsection{Conditional Optimality of Production Decision}

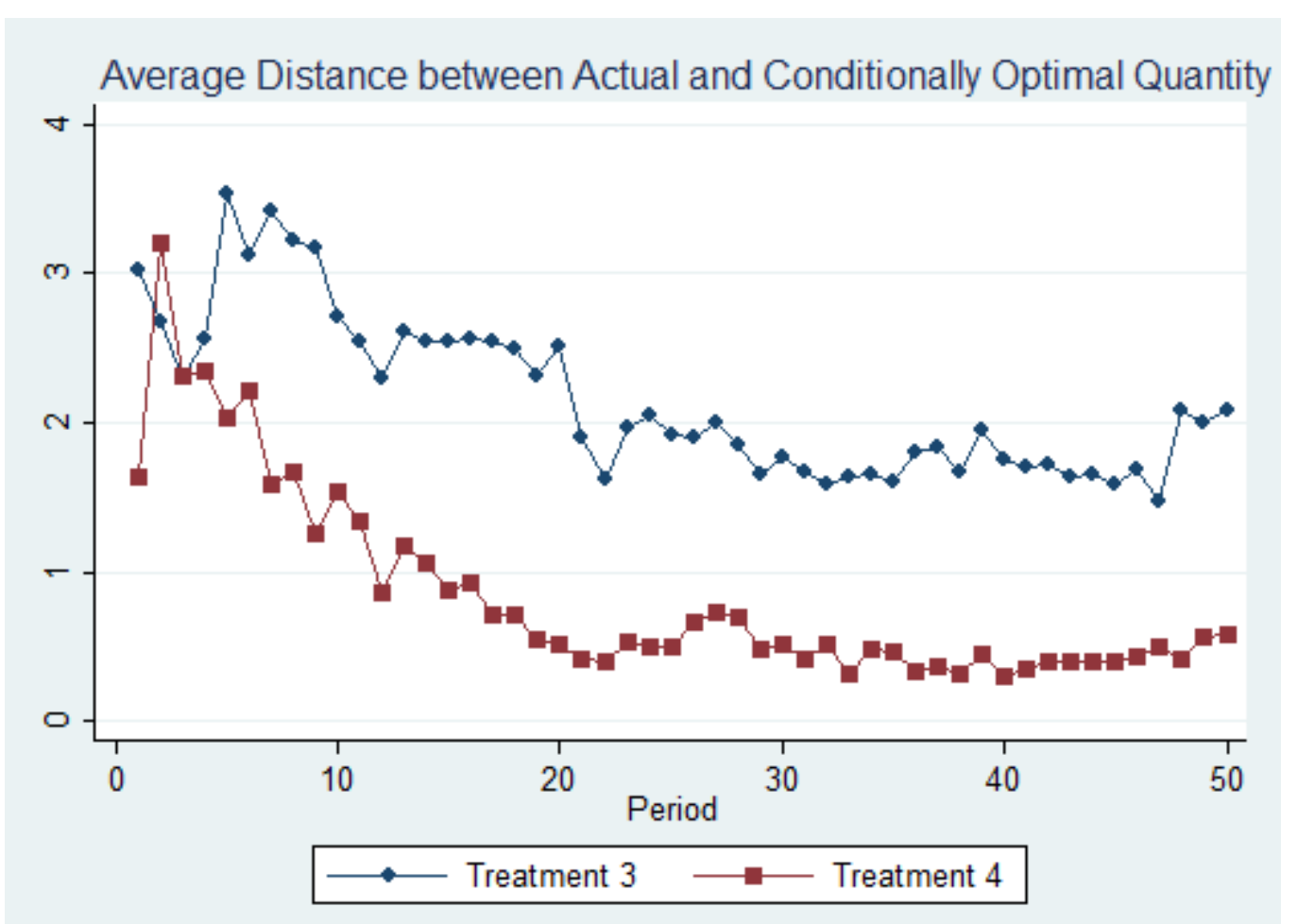

Figure 8: The average distance between actual supply and the conditionally optimal supply in Treatments 3 and 4.

If the production manager acts optimally with respect to the forecaster's forecast, he should decide to supply $1 / 6$ of the firm's price prediction. Do production managers make decisions in this manner? Figure 8 shows the average difference between the supply chosen by the production manager and the optimal supply given his own or his paired forecaster's forecast in treatments 3 and 4, respectively. If the production managers make decisions optimally, this difference should be zero.

Figure 8 reveals that the production managers in treatment 4 on average make 
supply decisions that are closer to the conditionally optimal quantity choie given their partners' price forecast. This also indicates that the production managers generally trust their partners. Although trust should not be an issue in treatment 3, where the forecast and supply decisions are made by the same person, we observe that subjects in treatment 3 generally fail to make production decisions that are optimal given their own price forecasts. We suspect that the reason for this difference in treatment 3 as compared with treatment 4 is that doing both tasks (as is required in treatment 3) is indeed very difficult for a single individual, that is, there is a greater cognitive load in treatment 3 as compared with treatment 4.

\subsubsection{Estimation of Supply Strategies}

We are interested in the possible cause of the deviation of managers' supply decisions from the conditionally optimal decision given price predictions in treatments 3 and 4 . To address this issue further, we estimate a simple production strategy specification:

$$
q_{t}=c_{0}+c_{1} p_{t}^{e}
$$

If the production manager is a conditional optimizer, the regression result should yield that $c_{0}=0, c_{1}=1 / 6$ for each individual firm. There are certainly many other independent variables that could also be included in the specification of the production decision. As the production managers in Treatment 4 do not see information such as the price forecast history, and the forecaster and production managers in Treatment 3 should have incorporated all other information into the predictions they made for themselves, this equation is most suitable for comparing the two treatments. We discard the estimations with serial correlation, leaving 13 (out of 42) successful

estimations for Treatment 3, and 18 (out of 36) successful estimations for Treatment 4. The results can be found in the Appendix C.

We can classify subjects in their role as production managers according to three types:

1. Unconditional supply, if $c_{0}$ is significantly different from 0 at $5 \%$, and $c_{1}$ is not. This means the subject probably just choose to supply a constant number of goods. 
2. Conditional optimal supply, if $c_{1}$ is significantly different from 0 at $5 \%, c_{0}$ is not significant, and the null hypothesis $c_{1}=1 / 6$ can not be rejected at $5 \%$ level. This means that the subject choose to supply the conditionally optimal quantity for the given price forecast.

3. Hybrid strategy, if both $c_{0}$ and $c_{1}$ are significant. This means that the subject probably choose a constant as a psychological anchor, and adjusted it a little for different expected price levels.

It turns out all the successful estimations can be classified in this way. The graph below shows the shares of the three different types of production strategies. We use $C$ to denote the use of the constant supply strategy, $O$ to denote use of the conditionally optimal supply strategy and $H$ to denote use of the hybrid strategy. There are 4 subjects using the constant supply strategy, 2 using the conditionally optimal supply strategy and 7 using a hybrid strategy in Treatment 3 . There is 1 subject using the constant supply strategy, 9 using the conditionally optimal supply strategy and 8 using the hybrid strategy in Treatment 4. Thus, about half of all subjects (for whom we could identify a supply strategy) use a hybrid strategy in both treatments. For the remaining population, a majority uses the constant supply strategy in Treatment 3 while in Treatment 4 , the majority uses the conditionally optimal strategy. This result suggests that subjects do behave in a systematically different manner between treatments 3 and 4 . In treatment 3, many subjects choose to use the constant supply strategy which requires minimal cognitive cost, but which destabilizes the market when they choose the wrong (usually too high) quantity. In

treatment 4 , subjects in the production manager role trust their partners's forecasts to a reasonable degree, which facilitates their greater use of the conditionally optimal strategy.

\section{Conclusion}

Rational Expectations (RE) macro models have two crucial dimensions: 1) Agents correctly forecast future prices (no systematic mistakes). 2) Given these expectations, agents solve optimization problems and their optimal production (or consumption or trading) strategies then determine actual price realizations, that is, there is 

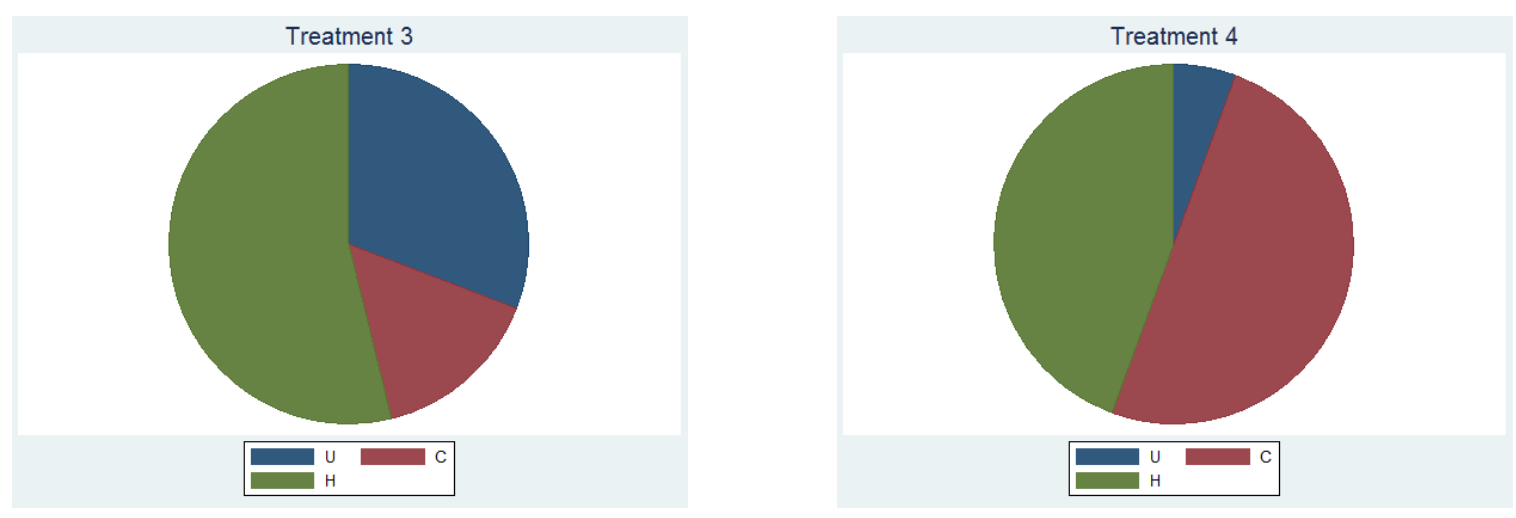

Figure 9: This graph shows the share of different types of estimated production strategies treatment 3 and 4 . We use $C$ to denote the use of the constant supply strategy, $O$ to denote use of the conditionally optimal supply strategy and $H$ to denote use of the hybrid strategy.

belief-outcome interaction. These two dimensions have been previously addressed separately in learning to forecast experiments (LtFE) and learning to optimize experiments (LtOE). In this paper we design comparable LtFE and LtOE treatments for the same model, and add two additional treatments where subjects perform both tasks either independently or as members of a team. Our paper shows that all the approaches give the same qualitative, long-run result, namely convergence to the REE in the context of cobweb economy.

Among all the treatments, the LtFE treatment converges more quickly and reliably than the other three treatments. We suspect this is because the forecasting task is considerably easier than the optimizing task and therefore behavior in LtFE studies should be regarded as an upper bound on the rationality that can be achieved in a laboratory experimental evaluation of RE models. The estimation of individual forecast rules suggests that there is not much difference in the price prediction strategies subjects use across the different treatments. However, estimation of the supply strategies suggests that there are differences in strategies used between treatments 3 and 4. The current macroeconomic literature usually only takes bounded rationality in forecasting into the theoretical models, and the implication of our result for future theoretical work is that it may be worthwhile to also take bounded rationality in optimization into account. 
We also find evidence in support of the notion that "two heads are better than one" in the sense that behavior in treatment 4 is more rational than that in treatment 3, even in the aspect of consistency (how close the production decision is to the conditionally optimal decision for the given price forecast). This finding also goes along with the real life observation that large financial institutes usually have separate forecasting and trading departments, and rarely let one department perform the task of the other.

In future research it would be desirable to consider experiments with comparable LtFE and LtOE treatments in different market contexts from the one considered here. In particular it would be of interest to apply our same approach to a market with positive expectation feedback, where prices usually doe not converge, at least in the learning to forecast experiments that have been used to date in such environments. 


\section{Reference}

1. Adam, K., "Experimental Evidence on the Persistence of Output and Inflation," Economic Journal, 117, 2007, 603-635.

2. Arifovic, J., "The Behavior of the Exchange Rate in the Genetic Algorithm and Experimental Economies", Journal of Political Economy, 104 (3), 510-541.

3. Bao, T., Hommes, C., Sonnemans, J., Tuinstra, J., "Individual Expectations, Limited Rationality and Aggregate Outcomes," Working Paper University of Amsterdam, 2010.

4. Bornstein, G., and I. Yaniv, "Individual and Group Behavior in the Ultimatum Game: Are Groups more 'Rational' Players?,' Experimental Economics, 1, 101108.

5. Cason, T., and V. Mui, "A Laboratory Study of Group Polarization in the Team Dictator Game," Economic Journal, 107, 1465-1483.

6. Cox, J. C., "Trust, Reciprocity, and Other-Regarding Preferences: Groups vs. Individuals and Males vs. Females," in (R. Zwick, and A. Rapoport, eds.), Advances in Experimental Business Research, pp. 331-50, Dordrecht: Kluwer Academic Publishers.

7. Crockett, S., and J. Duffy, "A Dynamic General Equilibrium Approach to Asset Pricing Experiments," Working Paper.

8. Duffy, J. "Macroeconomics: A Survey of Laboratory Research", working paper, University of Pittsburgh, 2008.

9. Fehr, E. and J.-R. Tyran, "Limited Rationality and Strategic Interaction: the Impact of the Strategic Environment on Nominal Inertia", Econometrica 76 (2008), 353-394.

10. Gode, D.K., and S. Sunder, "Allocative Efficiency of Markets with Zero-Intelligence Traders: Market as a Partial Substitute for Individual Rationality," Journal of Political Economy, 101(1), 119-137.

11. Heemeijer, P., Hommes, C., Sonnemans J., and J. Tuinstra, "Price Stability and Volatility in Markets with Positive and Negative Expectations Feedback: 
An Experimental Investigation," Journal of Economic Dynamics and Control 33 (2009), 1052-1072

12. Hommes, C.H., Sonnemans, J.H., Tuinstra, J. and van de Velden, H., "Coordination of Expectations in Asset Pricing Experiments," Review of Financial Studies, 2005, 18 (3), 955-980.

13. Hommes, C.H., Sonnemans, J.H., Tuinstra, J.,and van de Velden, H., "Learning in Cobweb Experiments", Macroeconomic Dynamics, 11, 2007, 8-33.

14. Huck, S., Norman, H.T., and J. Oechssler, "Learning in Cournot Oligopoly-An Experiment," Economic Journal, 109 (454), 80-95.

15. Kocher, M., and M. Sutter, "When the 'Decision-maker' Matters: Individual versus Team Behavior in Experimental 'Beauty Contest' Games," Economic Journal, 115, 200-223.

16. Lim S.S., E.C. Prescott and S. Sunder, "Stationary Solution to the Overlapping Generations Model of Fiat Money: Experimental Evidence," Empirical Economics, 19, 1994, 255-77.

17. Marimon, R. and S. Sunder, "Indeterminacy of Equilibria in a Hyperinflationary World: Experimental Evidence," Econometrica, 61(5), 1993, 1073-1107.

18. Marimon, R. and S. Sunder, "Expectations and Learning under Alternative Monetary Regimes: An Experimental Approach," Economic Theory, 4, 1994, 131-62.

19. Marimon, R., Spear, S. E., and S. Sunder, "Expectationally Driven Market Volatility: An Experimental Study," Journal of Economic Theory, 61(1), 1993, 74-103.

20. Muth, J.F., "Rational Expectations and the Theory of Price Movements," Econometrica, 29(3), 1961, 315-335.

21. Offerman, T., Potters, J., and J. Sonnemans, "Imitation and Belief Learning in an Oligopoly Experiment," Review of Economic Studies 69, 973-97.

22. Smith, V. L., Suchanek. G. L. and A. W. Williams, "Bubbles, Crashes, and Endogenous Expectations in Experimental Spot Asset Markets," Econometrica, 56(5), 1988, 1119-1151. 
23. Vega-Redondo, F., "The Evolution of Walrasian Behavior," Econometrica, 65(2), 375-384. 


\section{A Appendix}

\section{A.1 Experimental Instructions}

\section{A.1.1 Instruction for the Forecaster}

(Normal for T1, in () for T4)

\section{General information}

In this experiment you participate in a market. Your role in the market is a professional Forecaster for a large firm, and the firm is a major Producer of one product sold in the market. In each period the firm asks you to make a prediction of the market price of the product. The price should be predicted one period ahead, since producing the good takes some time. You are going to advise the firm for 50 successive time periods. (At the beginning of the experiment, you and another participant a Production Manager as your partner are assigned into a team and will keep cooperating throughout the experiment.) In each period you have to make a prediction for the price in the next period, and your firm (partner) makes a decision about the quantity of the good the firm should produce. Your forecast is the only information the firm (production manager) has on the future market price. The more accurate your prediction is, the better the quality of your firm's (partner's) decision will be, and the more profit your firm can earn. In each period, (each of) you (and your partner) will get a payoff based on the accuracy of your prediction (and the quality of production decisions).

The information you can refer to consists of a plot of the past prices and your predictions, a table containing the history of your past forecasts, [production decisions] and payoff (of your team) in forecasting [(and production)] tasks. (You partner sees a plot of the past price, a table containing the history of his/her supply decisions and the payoff of your team in forecasting and production tasks.)

\section{About the price determination}

The price is determined by the market clearing condition, meaning that it will be such that the supply equals demand. 
The supply on the market is determined by the production decision of the producers. There are several large producers on this market and each of them is advised by a forecaster like you. Usually, higher price predictions make a firm to produce a larger quantity, which increases the supply and vise versa. Total supply is largely determined by the sum of the individual supplies of these producers, although there may be small random fluctuations caused by transportation delay or other reasons.

The size of the demand depends upon the price. When the price goes up, the demand will go down.

\section{About your job}

Your only task in this experiment is to predict the market price in each time period as accurately as possible. At the beginning of the experiment you are asked to give a prediction for the price period 1. When all forecasters have submitted their predictions for the first period, the firms (production managers) will determine the quantity to supply, and the market price for period 1 will be determined and made public to

all forecasters. Based the accuracy of your prediction in period 1, your earnings will be calculated.

Subsequently, you are asked to enter your prediction for period 2. When all participants have submitted their prediction [(and production decisions)] for the second period, the market price for that period will be made public and your earnings will be calculated, and so on, for all 50 consecutive periods. The information you can refer to consists of all previous prices, your predictions and earnings.

\section{About your payoff}

You payoff depends on the (both) performance of your forecasting task (and your partner's production decision task. Each of you and your partner will get one half of the payoff for the forecasting task and one half of the payoff for the quantity production task). The payoff for the forecasting task depends on the accuracy of your predictions. The earnings shown on the computer screen will be in terms of points. The maximum possible points you can make for the forecasting task is 1300 for each period, and the larger your prediction error is, the fewer points you can make. You will earn 0 points if your prediction error is larger than 7 . There is a Payoff Table on your table, which shows the points you can earn for different prediction errors. Your action will have no impact on the payoff from the production task. 
We will pay you in cash at the end of the experiment based on the points you earned. You earn 1 euro for each 2600 points you make.

\section{A.1.2 Instruction for the Production Manager}

(Normal for T2, in () for T4, and [] for T3)

\section{General information}

In this experiment you participate in a market. Your role in the market is a Production Manager of a large firm, and the firm is a major Producer of one product sold in the market. In each period the firm asks you to make a decision on the quantity your firm will supply to the market. You are going to play this role for 50 successive time periods.

(At the beginning of the experiment, you and another participant, a Forecaster as your partner are assigned into a team and will keep cooperating throughout the experiment. In each period you will receive a prediction for the price in this period from your partner, and make a decision about how much goods your firm should produce.) The better the quality of your decision is, the more profit your firm can earn. The information you can refer to consists of a plot of the past prices, a table containing the history of your past decisions and the payoff (of your team) in (forecasting and) production tasks. (You partner sees a plot of the past price and his/her own forecasts, a table containing the history of his/her past forecasts and the payoff of your team in forecasting and production tasks. )

\section{About the price determination}

The price is determined by the market clearing condition, meaning that it will be such that the supply equals demand.

The supply on the market is determined by the production decision of the producers. Usually, higher price predictions make a firm to produce a larger quantity, which increases the supply and vise versa. Total supply is largely determined by the sum of the individual supplies of these producers, although there may be small random fluctuations caused by transportation delay or other reasons. 
The size of the demand depends upon the price. When the price goes up, the demand will go down.

\section{About your job}

Your task in this experiment is to [make a prediction on the market price and] decide the quantity the firm will supply. At the beginning of the experiment (you receive the forecaster's prediction for the price period 1. When all forecasters have submitted their predictions for the first period, the decision makers including) [you make a prediction of the market price and] you determine the quantity to supply for period 1, and when all the participants submitted their [forecasts and] decisions, the market price for period 1 will be determined and made public to all forecasters. Based on [the accuracy of your prediction and] the profit of your firm in period 1, your earnings in the first period will be calculated.

Subsequently, (you receive the forecaster's prediction for period 2, and) you make [the prediction and] the production decisions for the second period. When all participants have submitted [their prediction and] production decisions for the second period, the market price for that period will be calculated and made public and your earnings will be calculated, and so on, for all 50 consecutive periods.

\section{About your payoff}

You payoff depends on the ([both]) performance of your production task ([and your] partner's [forecasting task.) Each of [you] and your partner [will get one half of the payoff for the forecasting task and one half of the payoff for the production task]).The payoff for the production task is the same as the profit of the firm. The earnings shown on the computer screen will be in terms of points. You do not need to calculate your payoff yourself. There is a Payoff Table for Production Task on your table, which shows the points you can earn for a given market price in the row (, [for which you could use your] partner's [forecast as a proxy) and your production decision in the column. You payoff from the forecasting task is decreasing in your prediction error, and you can also refer to the other payoff table to see how much you can earn for a given prediction error. ] If you really want to know how the numbers in the payoff table is calculated you can read the last part of the instruction, which you can skip 
otherwise.

We will pay you in cash at the end of the experiment based on the points you earned. You earn 1 euro for each 2600 points you make.

The equation that calculates the payoff for the production task

The payoff for production task can be written as the following equation:

$$
\text { Payoff from the Production Task }=p_{t} q_{t}-c\left(q_{t}\right)+1200
$$

Where $p_{t}$ is the market price of this good, and you can use your partner's prediction as a proxy. $q_{t}$ is the amount of product you decide to let the firm produce. $c\left(q_{t}\right)=3 q_{t}^{2}$ , which is the cost function. Therefore $p_{t} q_{t}-c\left(q_{t}\right)$ is the net profit of the firm, which coincides in numbers with your bonus. The higher the profit of the firm, the higher your bonus will be. You get 1200 points as the basis salary. The profit of the firm can be negative, so the payoff from the production task can be smaller than 1200 .

\section{B Testing Convergence using Linear Estimation}

\section{Identified Forecasting Rules}

\section{Estimated Supply Strategies}

E Payoff Tables

\section{E.1 Payoff Table for Forecasters}

\section{E.2 Payoff Table for Production Managers}




\begin{tabular}{ccccccc}
\hline \hline market & $\lambda$ & $\mu$ & $R^{2}$ & MSE & Equilibrium & P-value Wald Test \\
\hline p11 & 0.1863 & 24.9741 & 0.1113 & 7.6785 & 30.6921 & 0.9378 \\
p12 & 0.1698 & 25.5817 & 0.1495 & 3.9079 & 30.8131 & 0.8073 \\
p13 & 0.2108 & 24.3511 & 0.1838 & 5.0071 & 30.8546 & 0.7586 \\
p14 & 0.1827 & 25.2209 & 0.1850 & 3.3689 & 30.8573 & 0.691 \\
p21 & 0.6059 & 11.5545 & 0.5238 & 18.1876 & 29.3174 & 0.3667 \\
p22 & 0.4733 & 15.3094 & 0.3085 & 30.4796 & 29.0684 & 0.2673 \\
p23 & 0.0056 & 30.0469 & 0.0001 & 6.3699 & 30.2151 & 0.1540 \\
p24 & 0.5191 & 14.8545 & 0.4287 & 17.8924 & 30.8868 & 0.9015 \\
p25 & 0.2666 & 22.3075 & 0.1239 & 21.9634 & 30.4165 & 0.7306 \\
p26 & 0.5411 & 14.4979 & 0.5543 & 9.7218 & 31.5946 & 0.3778 \\
p27 & 0.2891 & 22.0542 & 0.2156 & 9.6062 & 31.0231 & 0.6383 \\
p31 & 0.4189 & 19.0151 & 0.3137 & 18.3482 & 32.7227 & 0.0597 \\
p32 & 0.4488 & 19.4622 & 0.2966 & 35.1703 & 35.3101 & 0.0028 \\
p33 & 0.4197 & 14.0236 & 0.1950 & 62.8946 & 24.1653 & 0.0008 \\
p34 & 0.2126 & 22.9448 & 0.0734 & 25.5324 & 29.1408 & 0.0818 \\
p35 & 0.2351 & 19.5698 & 0.0896 & 18.9326 & 25.5849 & 0.0000 \\
p36 & 0.1740 & 23.0230 & 0.0974 & 6.4048 & 27.8739 & 0.0000 \\
p37 & 0.7604 & 5.5085 & 0.6605 & 20.8671 & 22.9902 & 0.0055 \\
p41 & 0.2182 & 25.0770 & 0.1149 & 12.9444 & 32.0757 & 0.0408 \\
p42 & 0.0674 & 28.1808 & 0.0093 & 17.4663 & 30.2188 & 0.4225 \\
p43 & 0.3334 & 19.9712 & 0.2167 & 14.7826 & 29.9588 & 0.3500 \\
p44 & 0.4994 & 14.6045 & 0.3604 & 23.8659 & 29.1717 & 0.2652 \\
p45 & 0.3080 & 20.7341 & 0.2789 & 6.6841 & 29.9616 & 0.1507 \\
p46 & 0.3530 & 19.2175 & 0.1990 & 23.6375 & 29.7035 & 0.3385 \\
\hline \hline & & & & & & \\
\hline
\end{tabular}

Table 7: This table shows the estimation results of $p_{j, t}=\lambda_{j} p_{j, t-1}+\mu_{j}+\epsilon_{j, t}$ on the markets from different treatments. The results start with $p_{11}$, which is the first market in treatment 1 , and through $p_{46}$, which is the sixth market in treatment 4. 


\begin{tabular}{|c|c|c|c|c|c|}
\hline Participant & Type & Coefficient & $p-$ value & $R^{2}$ & MSE \\
\hline $\exp 12$ & $\mathrm{~A}$ & 0.7694 & 0.0000 & 0.3903 & 2.3471 \\
\hline exp13 & A & 0.7377 & 0.0000 & 0.3061 & 6.4884 \\
\hline exp14 & A & 0.8699 & 0.0000 & 0.4108 & 5.7149 \\
\hline exp16 & $\mathrm{C}$ & -0.3954 & 0.0000 & -0.4849 & 3.0398 \\
\hline $\exp 21$ & A & 0.4213 & 0.0000 & 0.3754 & 0.8548 \\
\hline $\exp 22$ & A & 0.8927 & 0.0000 & 0.3079 & 3.3428 \\
\hline $\exp 23$ & A & 0.5972 & 0.0000 & -0.0826 & 2.8951 \\
\hline $\exp 24$ & A & 0.7315 & 0.0000 & 0.5123 & 2.1833 \\
\hline $\exp 26$ & A & 0.869 & 0.0000 & 0.5607 & 1.6952 \\
\hline exp32 & A & 0.8157 & 0.0000 & 0.0349 & 18.6036 \\
\hline exp33 & A & 0.7843 & 0.0000 & 0.3526 & 5.3878 \\
\hline exp34 & $\mathrm{C}$ & -0.8417 & 0.0000 & 0.4292 & 2.3739 \\
\hline exp35 & $\mathrm{A}$ & 0.8046 & 0.0000 & 0.1779 & 10.4585 \\
\hline exp36 & A & 0.5127 & 0.0000 & 0.1428 & 1.0798 \\
\hline $\exp 41$ & A & 0.9088 & 0.0000 & 0.0314 & 19.9845 \\
\hline $\exp 42$ & A & 0.4992 & 0.0000 & 0.6754 & 0.5255 \\
\hline $\exp 43$ & $\mathrm{C}$ & 0.0179 & 0.0000 & 0.5062 & 1.2445 \\
\hline $\exp 44$ & A & 0.7407 & 0.0000 & 0.6352 & 0.8499 \\
\hline $\exp 45$ & A & 0.8464 & 0.0000 & 0.5273 & 0.9977 \\
\hline
\end{tabular}

Table 8: This table shows the estimation results for the subjects who can successfully categorized by one forecasting rule in Treatment 1 . In the "Type" column, "A" means adaptive rule, "C" means contrarian/trend extrapolation rule. 


\begin{tabular}{|c|c|c|c|c|c|}
\hline Participant & Type & Coefficient & $p-$ value & $R^{2}$ & MSE \\
\hline exp11 & $\mathrm{A}$ & 0.9247 & 0.0000 & 0.568 & 9.1737 \\
\hline exp12 & $\mathrm{C}$ & -0.4489 & 0.0000 & 0.4915 & 5.4309 \\
\hline exp13 & $\mathrm{A}$ & 0.8778 & 0.0000 & 0.4717 & 14.7741 \\
\hline exp14 & $\mathrm{A}$ & 0.9245 & 0.0000 & 0.4849 & 10.3821 \\
\hline exp16 & $\mathrm{A}$ & 0.673 & 0.0000 & 0.1749 & 12.4204 \\
\hline exp21 & $\mathrm{A}$ & 0.8436 & 0.0000 & 0.6769 & 12.1518 \\
\hline $\exp 22$ & $\mathrm{C}$ & -0.6319 & 0.0000 & 0.6336 & 10.343 \\
\hline $\exp 23$ & $\mathrm{C}$ & -0.4639 & 0.0000 & 0.4633 & 10.0276 \\
\hline $\exp 24$ & $\mathrm{C}$ & -0.4922 & 0.0000 & 0.6665 & 8.8984 \\
\hline $\exp 25$ & $\mathrm{~A}$ & 0.7225 & 0.0000 & 0.6602 & 11.5174 \\
\hline $\exp 26$ & $\mathrm{C}$ & -0.7042 & 0.0000 & 0.3808 & 22.5964 \\
\hline exp31 & $\mathrm{A}$ & 0.7621 & 0.0000 & 0.1423 & 76.3659 \\
\hline exp32 & A & 0.5417 & 0.0000 & 0.5974 & 24.5421 \\
\hline exp33 & $\mathrm{A}$ & 0.6442 & 0.0000 & 0.724 & 10.3266 \\
\hline exp34 & $\mathrm{A}$ & 0.6899 & 0.0000 & 0.468 & 26.425 \\
\hline exp36 & $\mathrm{C}$ & 0.6408 & 0.0000 & 0.7821 & 10.767 \\
\hline $\exp 51$ & $\mathrm{~A}$ & 0.4989 & 0.0000 & 0.513 & 5.803 \\
\hline exp52 & $\mathrm{C}$ & -0.153 & 0.0003 & 0.7033 & 2.943 \\
\hline exp53 & $\mathrm{A}$ & 0.7542 & 0.0000 & 0.4008 & 9.3458 \\
\hline exp54 & $\mathrm{A}$ & 0.4362 & 0.0000 & 0.4895 & 6.6524 \\
\hline exp55 & $\mathrm{A}$ & 0.7914 & 0.0000 & 0.3238 & 44.0411 \\
\hline exp56 & $\mathrm{A}$ & 0.9086 & 0.0000 & 0.5106 & 11.6252 \\
\hline exp61 & $\mathrm{A}$ & 0.584 & 0.0000 & -0.3159 & 2.7391 \\
\hline exp62 & $\mathrm{A}$ & 0.8386 & 0.0000 & 0.758 & 1.3188 \\
\hline exp63 & $\mathrm{A}$ & 0.8655 & 0.0000 & 0.9578 & 0.1774 \\
\hline $\exp 65$ & $\mathrm{~A}$ & 0.7223 & 0.0000 & 0.8278 & 0.7259 \\
\hline exp66 & $\mathrm{C}$ & 0.0356 & 0.0000 & 0.5704 & 3.2036 \\
\hline exp72 & $\mathrm{A}$ & 0.416 & 0.0000 & 0.8604 & 7.1865 \\
\hline $\exp 73$ & $\mathrm{C}$ & -0.1777 & 0.0004 & 0.9276 & 2.8821 \\
\hline $\exp 74$ & A & 0.2722 & 0.0001 & 0.6247 & 24.5324 \\
\hline $\exp 75$ & $\mathrm{C}$ & -0.4258 & 0.0000 & 0.8927 & 6.3127 \\
\hline $\exp 76$ & A & 0.4953 & 0.0000 & 0.8135 & 6.8963 \\
\hline
\end{tabular}

Table 9: This table shows the estimation results for the subjects who can successfully categorized by one forecasting rule in Treatment 3. In the "Type" column, "A" means adaptive rule, "C" means contrarian/trend extrapolation rule. 


\begin{tabular}{|c|c|c|c|c|c|}
\hline Participant & Type & Coefficient & $p-$ value & $R^{2}$ & MSE \\
\hline exp11 & $\mathrm{A}$ & 0.6495 & 0.0000 & 0.8129 & 2.0813 \\
\hline exp12 & $\mathrm{C}$ & -0.4201 & 0.0000 & 0.0841 & 5.7926 \\
\hline $\exp 14$ & $\mathrm{C}$ & -0.0851 & 0.0000 & 0.3344 & 8.1675 \\
\hline $\exp 16$ & $\mathrm{C}$ & -0.3519 & 0.0000 & 0.0871 & 4.6497 \\
\hline $\exp 21$ & $\mathrm{C}$ & -0.2769 & 0.0000 & 0.3691 & 7.351 \\
\hline $\exp 22$ & $\mathrm{C}$ & -0.6555 & 0.0000 & 0.7364 & 3.8006 \\
\hline $\exp 25$ & $\mathrm{C}$ & -0.352 & 0.0011 & 0.2997 & 19.7205 \\
\hline $\exp 26$ & A & 0.8179 & 0.0000 & 0.8584 & 1.7657 \\
\hline exp31 & A & 0.8627 & 0.0000 & 0.7207 & 4.3887 \\
\hline exp32 & A & 0.507 & 0.0000 & 0.6858 & 2.4103 \\
\hline exp33 & A & 0.4594 & 0.0000 & 0.4918 & 5.3313 \\
\hline exp34 & A & 0.777 & 0.0000 & 0.866 & 1.4416 \\
\hline exp35 & A & 0.6202 & 0.0000 & 0.5198 & 6.4221 \\
\hline exp36 & $\mathrm{C}$ & -0.3001 & 0.0169 & -0.1436 & 18.7005 \\
\hline $\exp 42$ & $\mathrm{C}$ & -0.6367 & 0.0000 & 0.7612 & 7.1209 \\
\hline $\exp 43$ & $\mathrm{C}$ & -0.5521 & 0.0000 & 0.7237 & 10.4271 \\
\hline $\exp 44$ & $\mathrm{~A}$ & 0.7716 & 0.0000 & 0.3301 & 15.5369 \\
\hline $\exp 46$ & $\mathrm{C}$ & -0.6195 & 0.0000 & 0.8119 & 4.7725 \\
\hline $\exp 51$ & $\mathrm{~A}$ & 0.8902 & 0.0000 & 0.2657 & 6.8258 \\
\hline exp52 & $\mathrm{A}$ & 0.5709 & 0.0000 & 0.3391 & 5.1909 \\
\hline $\exp 53$ & $\mathrm{~A}$ & 0.7164 & 0.0000 & 0.3517 & 4.646 \\
\hline $\exp 54$ & $\mathrm{~A}$ & 0.6875 & 0.0000 & 0.8253 & 0.9544 \\
\hline $\exp 55$ & $\mathrm{~A}$ & 0.7167 & 0.0000 & 0.6162 & 1.3439 \\
\hline $\exp 56$ & $\mathrm{~A}$ & 0.865 & 0.0000 & 0.4349 & 4.2283 \\
\hline exp62 & $\mathrm{A}$ & 0.8027 & 0.0000 & 0.4998 & 12.045 \\
\hline $\exp 63$ & $\mathrm{~A}$ & 0.7674 & 0.0000 & 0.4927 & 15.8082 \\
\hline exp64 & $\mathrm{A}$ & 0.6532 & 0.0000 & 0.9321 & 1.3295 \\
\hline exp66 & A & 0.9196 & 0.0000 & 0.7403 & 7.6132 \\
\hline
\end{tabular}

Table 10: This table shows the estimation results for the subjects who can successfully categorized by one forecasting rule in Treatment 4 . In the "Type" column, "A" means adaptive rule, "C" means contrarian/trend extrapolation rule. 


\begin{tabular}{|c|c|c|c|c|c|c|c|}
\hline \multicolumn{8}{|c|}{ 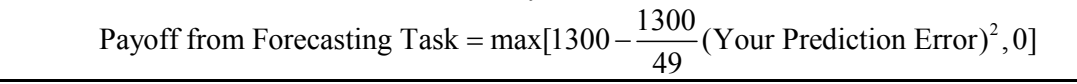 } \\
\hline \multicolumn{8}{|c|}{1300 points equal 0.5 euro } \\
\hline error & points & error & points & error & points & error & points \\
\hline 0 & 1300 & 1.85 & 1209 & 3.7 & 937 & 5.55 & 483 \\
\hline 0.05 & 1300 & 1.9 & 1204 & 3.75 & 927 & 5.6 & 468 \\
\hline 0.1 & 1300 & 1.95 & 1199 & 3.8 & 917 & 5.65 & 453 \\
\hline 0.15 & 1299 & 2 & 1194 & 3.85 & 907 & 5.7 & 438 \\
\hline 0.2 & 1299 & 2.05 & 1189 & 3.9 & 896 & 5.75 & 423 \\
\hline 0.25 & 1298 & 2.1 & 1183 & 3.95 & 886 & 5.8 & 408 \\
\hline 0.3 & 1298 & 2.15 & 1177 & 4 & 876 & 5.85 & 392 \\
\hline 0.35 & 1297 & 2.2 & 1172 & 4.05 & 865 & 5.9 & 376 \\
\hline 0.4 & 1296 & 2.25 & 1166 & 4.1 & 854 & 5.95 & 361 \\
\hline 0.45 & 1295 & 2.3 & 1160 & 4.15 & 843 & 6 & 345 \\
\hline 0.5 & 1293 & 2.35 & 1153 & 4.2 & 832 & 6.05 & 329 \\
\hline 0.55 & 1292 & 2.4 & 1147 & 4.25 & 821 & 6.1 & 313 \\
\hline 0.6 & 1290 & 2.45 & 1141 & 4.3 & 809 & 6.15 & 297 \\
\hline 0.65 & 1289 & 2.5 & 1134 & 4.35 & 798 & 6.2 & 280 \\
\hline 0.7 & 1287 & 2.55 & 1127 & 4.4 & 786 & 6.25 & 264 \\
\hline 0.75 & 1285 & 2.6 & 1121 & 4.45 & 775 & 6.3 & 247 \\
\hline 0.8 & 1283 & 2.65 & 1114 & 4.5 & 763 & 6.35 & 230 \\
\hline 0.85 & 1281 & 2.7 & 1107 & 4.55 & 751 & 6.4 & 213 \\
\hline 0.9 & 1279 & 2.75 & 1099 & 4.6 & 739 & 6.45 & 196 \\
\hline 0.95 & 1276 & 2.8 & 1092 & 4.65 & 726 & 6.5 & 179 \\
\hline 1 & 1273 & 2.85 & 1085 & 4.7 & 714 & 6.55 & 162 \\
\hline 1.05 & 1271 & 2.9 & 1077 & 4.75 & 701 & 6.6 & 144 \\
\hline 1.1 & 1268 & 2.95 & 1069 & 4.8 & 689 & 6.65 & 127 \\
\hline 1.15 & 1265 & 3 & 1061 & 4.85 & 676 & 6.7 & 109 \\
\hline 1.2 & 1262 & 3.05 & 1053 & 4.9 & 663 & 6.75 & 91 \\
\hline 1.25 & 1259 & 3.1 & 1045 & 4.95 & 650 & 6.8 & 73 \\
\hline 1.3 & 1255 & 3.15 & 1037 & $\begin{array}{l}5 \\
\end{array}$ & 637 & 6.85 & 55 \\
\hline 1.35 & 1252 & 3.2 & 1028 & 5.05 & 623 & 6.9 & 37 \\
\hline 1.4 & 1248 & 3.25 & 1020 & 5.1 & 610 & 6.95 & 19 \\
\hline 1.45 & 1244 & 3.3 & 1011 & 5.15 & 596 & error $\geq 7$ & 0 \\
\hline 1.5 & 1240 & 3.35 & 1002 & 5.2 & 583 & & \\
\hline 1.55 & 1236 & 3.4 & 993 & 5.25 & 569 & & \\
\hline 1.6 & 1232 & 3.45 & 984 & 5.3 & 555 & & \\
\hline 1.65 & 1228 & 3.5 & 975 & 5.35 & 541 & & \\
\hline 1.7 & 1223 & 3.55 & 966 & 5.4 & 526 & & \\
\hline 1.75 & 1219 & 3.6 & 956 & 5.45 & 512 & & \\
\hline 1.8 & 1214 & 3.65 & 947 & 5.5 & 497 & & \\
\hline
\end{tabular}

Figure 10: The payoff table for forecasters. 


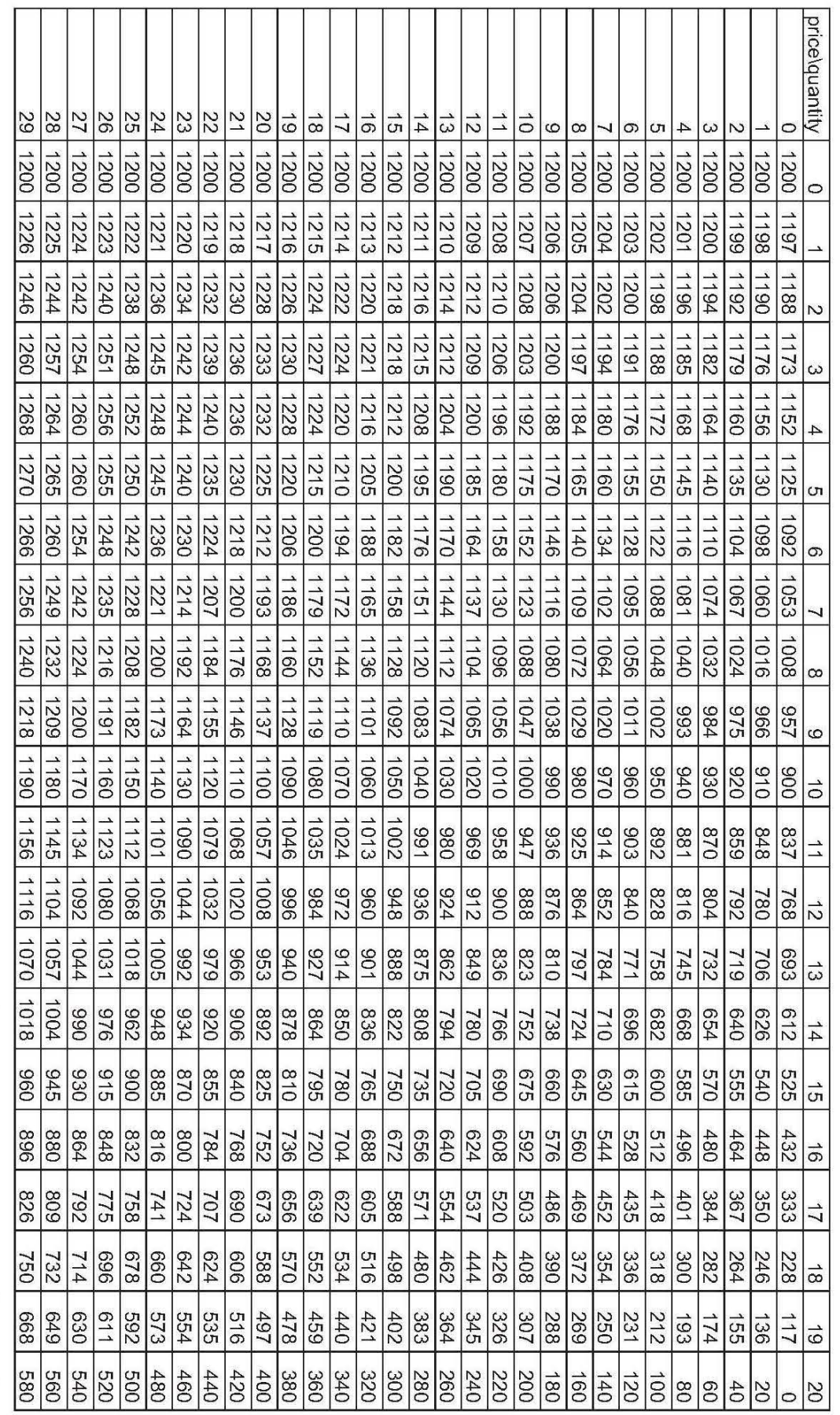

Figure 11: The payoff table for production managers, page 1. 


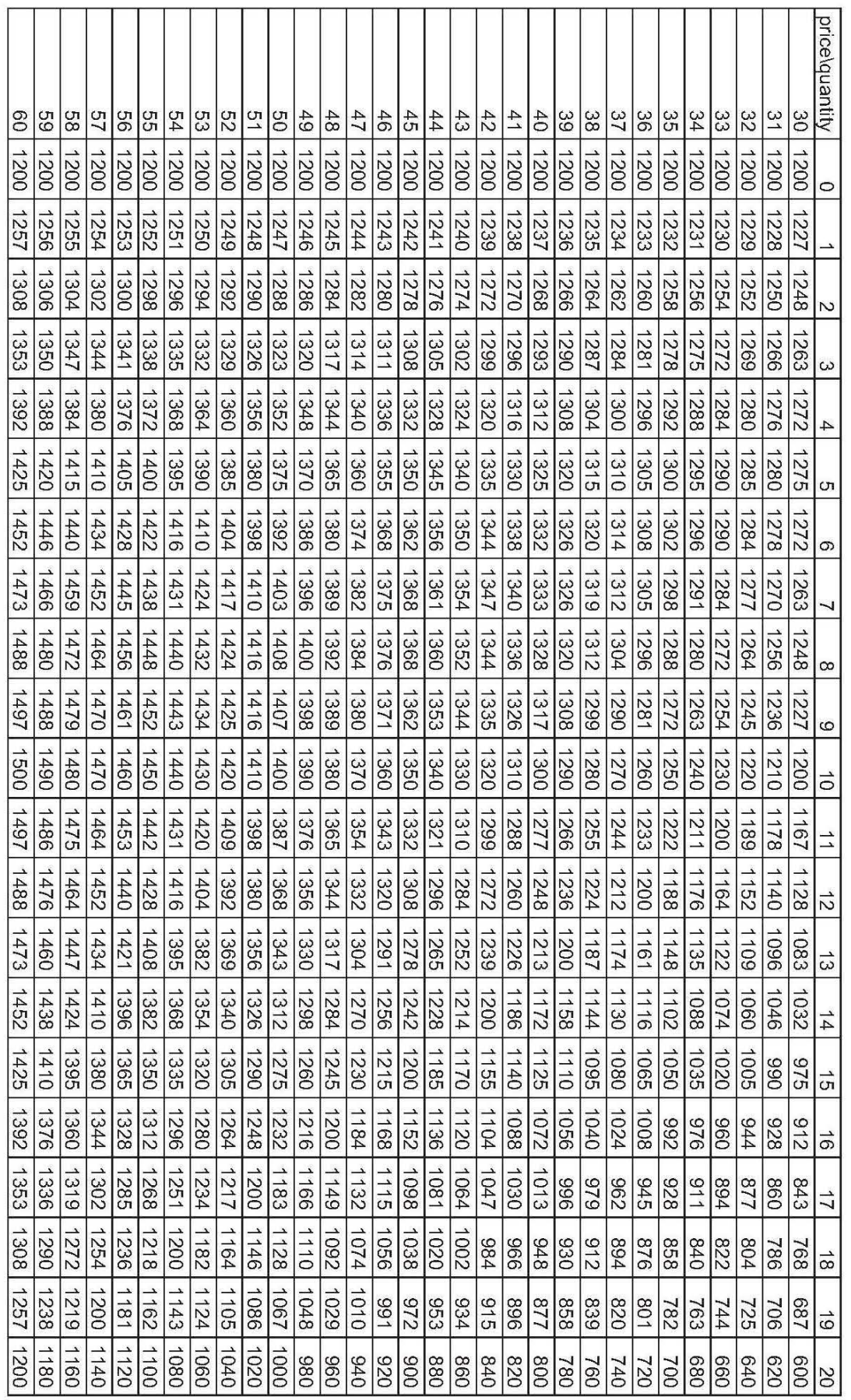

Figure 12: The payoff table for production managers, page 2. 


\begin{tabular}{cccccccc}
\hline \hline Participant & $c_{0}$ & $\mathrm{p}$-value & $c_{1}$ & $\mathrm{p}$-value & $R^{2}$ & $\mathrm{MSE}$ & Type \\
\hline exp13 & 3.6256 & 0.0006 & 0.0270 & 0.4007 & 0.0145 & 1.6985 & $\mathrm{C}$ \\
exp14 & 6.6367 & 0.0250 & -0.0437 & 0.6285 & 0.0049 & 8.3384 & $\mathrm{C}$ \\
exp15 & 2.2833 & 0.0328 & 0.0986 & 0.0030 & 0.1552 & 0.6952 & $\mathrm{H}$ \\
exp21 & -0.0537 & 0.9133 & 0.1656 & 0.0000 & 0.7515 & 0.4390 & $\mathrm{O}$ \\
exp24 & 15.5911 & 0.0000 & -0.2960 & 0.0001 & 0.2346 & 12.4429 & $\mathrm{H}$ \\
exp25 & 9.7377 & 0.0000 & -0.0963 & 0.0409 & 0.0801 & 3.8086 & $\mathrm{H}$ \\
$\exp 26$ & 17.9097 & 0.0000 & -0.4436 & 0.0000 & 0.6938 & 3.9053 & $\mathrm{H}$ \\
$\exp 42$ & 9.9127 & 0.0000 & -0.1609 & 0.0003 & 0.2166 & 2.4122 & $\mathrm{H}$ \\
$\exp 46$ & 8.0166 & 0.0000 & -0.0318 & 0.3819 & 0.0157 & 2.0399 & $\mathrm{C}$ \\
$\operatorname{exp54}$ & 3.8616 & 0.0001 & 0.0241 & 0.5690 & 0.0067 & 1.1388 & $\mathrm{C}$ \\
$\operatorname{exp55}$ & 2.1090 & 0.0000 & 0.0726 & 0.0002 & 0.2287 & 1.1636 & $\mathrm{H}$ \\
$\exp 63$ & 1.7970 & 0.0243 & 0.1129 & 0.0001 & 0.2470 & 0.2817 & $\mathrm{H}$ \\
$\exp 64$ & 0.6905 & 0.1161 & 0.1613 & 0.0000 & 0.6936 & 0.2877 & $\mathrm{O}$ \\
\hline \hline
\end{tabular}

Table 11: This table shows the estimated coefficients of the supply strategy used by the subjects in Treatment 3. 


\begin{tabular}{cccccccc}
\hline \hline Participant & $c_{0}$ & $\mathrm{p}$-value & $c_{1}$ & $\mathrm{p}$-value & $R^{2}$ & MSE & Type \\
\hline $\mathrm{q} 12$ & 0.3517 & 0.5014 & 0.1531 & 0.0000 & 0.6296 & 0.0969 & $\mathrm{O}$ \\
$\mathrm{q} 13$ & 2.8890 & 0.0000 & 0.0670 & 0.0000 & 0.3376 & 0.0800 & $\mathrm{H}$ \\
$\mathrm{q} 14$ & 0.0648 & 0.9744 & 0.1748 & 0.0060 & 0.1357 & 4.4876 & $\mathrm{O}$ \\
$\mathrm{q} 16$ & 3.9698 & 0.0000 & 0.0318 & 0.0041 & 0.1467 & 0.0519 & $\mathrm{H}$ \\
$\mathrm{q} 21$ & 0.1838 & 0.6911 & 0.1642 & 0.0000 & 0.7061 & 0.1834 & $\mathrm{O}$ \\
$\mathrm{q} 22$ & 0.7196 & 0.0125 & 0.1391 & 0.0000 & 0.8170 & 0.0691 & $\mathrm{H}$ \\
$\mathrm{q} 23$ & 2.7288 & 0.0348 & 0.0788 & 0.0769 & 0.0612 & 1.1603 & $\mathrm{C}$ \\
$\mathrm{q} 26$ & 0.3254 & 0.8720 & 0.1643 & 0.0109 & 0.1191 & 3.7786 & $\mathrm{O}$ \\
$\mathrm{q} 31$ & 6.4322 & 0.0000 & -0.0349 & 0.3841 & 0.0155 & 1.4020 & $\mathrm{H}$ \\
$\mathrm{q} 32$ & 0.4993 & 0.0965 & 0.1535 & 0.0000 & 0.8184 & 0.0906 & $\mathrm{O}$ \\
$\mathrm{q} 33$ & 1.4861 & 0.0373 & 0.1191 & 0.0000 & 0.3333 & 0.2983 & $\mathrm{H}$ \\
$\mathrm{q} 34$ & 0.9924 & 0.4204 & 0.1424 & 0.0004 & 0.2055 & 1.4840 & $\mathrm{O}$ \\
$\mathrm{q} 35$ & 3.4949 & 0.0007 & 0.0515 & 0.1297 & 0.0457 & 0.8554 & $\mathrm{H}$ \\
$\mathrm{q} 43$ & 13.4421 & 0.0000 & -0.2624 & 0.0000 & 0.6169 & 1.8068 & $\mathrm{H}$ \\
$\mathrm{q} 45$ & 0.3209 & 0.2657 & 0.1558 & 0.0000 & 0.8434 & 0.0975 & $\mathrm{O}$ \\
$\mathrm{q} 54$ & 2.1929 & 0.0000 & 0.0936 & 0.0000 & 0.3941 & 0.0739 & $\mathrm{H}$ \\
$\mathrm{q} 56$ & 0.2222 & 0.4602 & 0.1563 & 0.0000 & 0.8465 & 0.0679 & $\mathrm{O}$ \\
$\mathrm{q} 62$ & -0.2469 & 0.2875 & 0.1733 & 0.0000 & 0.9171 & 0.0828 & $\mathrm{O}$ \\
\hline \hline
\end{tabular}

Table 12: This table shows the estimated coefficients of the supply strategy used by the subjects in Treatment 4 . We use $C$ to denote the use of the constant supply strategy, $O$ to denote use of the conditionally optimal supply strategy and $H$ to denote use of the hybrid strategy. 